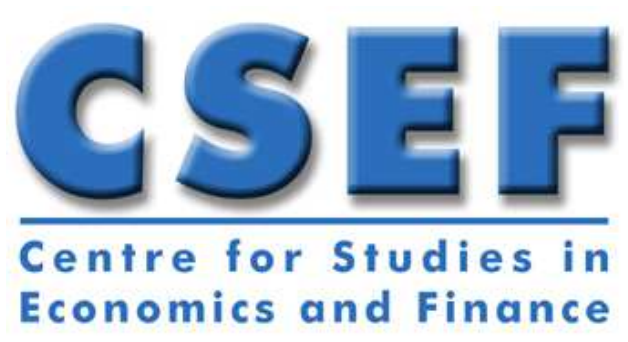

\title{
Working Paper no. 564
}

\section{Vertical Price Restraints and Free Entry \\ Under Asymmetric Information}

Leda Maria Bonazzi, Raffaele Fiocco and Salvatore Piccolo

May 2020
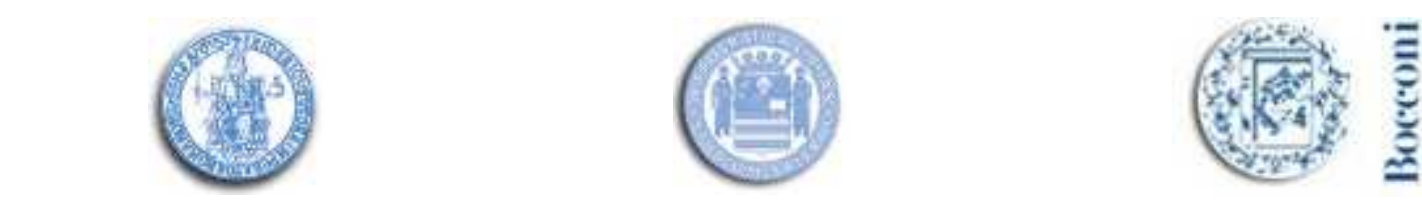

CSEF - Centre for Studies in Economics and Finance DEPARTMENT OF ECONOMICS - UNIVERSITY OF NAPLES 80126 NAPLES - ITALY

Tel. and fax +39081 675372 - e-mail: csef@unina.it ISSN: 2240-9696 



\title{
Working Paper no. 564
}

\section{Vertical Price Restraints and Free Entry Under Asymmetric Information}

\author{
Leda Maria Bonazzi", Raffaele Fiocco** and Salvatore Piccolo***
}

\begin{abstract}
We investigate the impact of vertical price restraints on the free-entry equilibrium and its welfare properties in a vertically related market where manufacturer-retailer hierarchies compete under asymmetric information. We compare the legal regimes of laissez-faire and ban on resale price maintenance (RPM) under different entry decision modes. When the entry decision is taken upstream, laissez-faire generates higher entry and increases consumer surplus, but a ban on RPM enhances total welfare. Socially excessive entry occurs under both legal regimes, and the entry bias declines with the spread of demand uncertainty. Conversely, when the entry decision is taken downstream, a ban on RPM stimulates entry and consumer surplus, but laissez-faire can be total welfare superior. Our results provide antitrust policy implications about vertical price control.
\end{abstract}

JEL classification: D82, L13, L42

Keywords: asymmetric information, free entry, quantity forcing, resale price maintenance, vertical restraints.

\footnotetext{
University of Essex. Email address: Ib19565@essex.ac.uk.

** Università di Bergamo. Email address: raffaele.fiocco@unibg.it

**** Università di Bergamo, Compass Lexecon, and CSEF. Email: salvatore.piccolo@unibg.it
} 



\section{Table of contents}

1. Introduction

2. The model

3. Complete information benchmark

4. Asymmetric information

5. Free-entry equilibrium and consumer surplus

6. Total welfare

7. Concluding remarks

Appendix

References 



\section{Introduction}

A primary concern for antitrust authorities in vertically related markets is the scrutiny of vertical restraints that manufacturers impose on their retailers. Vertical arrangements are typically adopted by firms operating at different stages of the production process for various reasons, such as the abatement of transaction costs, the guarantee of supply stability, and better coordination of actions (e.g., Motta 2004). A prominent example is resale price maintenance (RPM), whereby the manufacturer affects the price that the retailer charges on final customers. The economic consequences of retail price restrictions have received considerable attention in the practical and theoretical debate for a long time. A classical argument in support of RPM, known as the Chicago School approach (e.g., Spengler 1950; Telser 1960) is that vertical price control allows manufacturers to remove negative externalities, such as double marginalization and free riding in the provision of services. More recently, this traditional view has been criticized by a number of contributions, notably Rey and Tirole (1986) and Jullien and Rey (2007), which characterize various anticompetitive effects of RPM. In particular, RPM can help manufacturers to increase their market power or facilitate upstream collusion.

The literature has focused so far on the short-run effects of vertical price restraints in market environments with an exogenous number of firms. In this paper, we attempt to enrich the current debate by analyzing the longer-run effects of vertical price restraints in a framework where the market structure is endogenously determined by free entry. In practice, the entry decision mode typically differs across markets. In various industries, including automobile, gasoline, fashion, hotels, fast food, ice-creams, and beer, leading manufacturers recruit exclusive retailers to distribute their products (e.g., Asker 2016; Bresnahan and Reiss 1990; Suzuki 2013). For instance, Toyota places automobile dealers, and Shell resorts to gasoline stations. In such industries, the decision to enter a market is arguably taken by manufacturers. In other industries, such as supermarkets and software, large retailers source their input from upstream suppliers. For instance, Walmart purchases consumer goods, and Apple buys processors. In these industries, the decision to enter a market is likely to be taken by retailers (e.g., Jia 2008; Tyagi 1999). As extensively documented by Blair and Lafontaine (2005), the relationship between manufacturers and retailers is often specified through franchising agreements, according to which the retailer pays the manufacturer for the right to sell the manufacturer's product or the right to use its trademarks.

In this paper, we compare two legal regimes: laissez-faire, under which RPM is allowed, and ban on RPM, under which this practice is prohibited. We show that the choice of the legal regime crucially affects the free-entry equilibrium and its welfare properties, which vary in a nontrivial manner with the entry decision mode. Specifically, our study raises several challenging questions. What is the impact of RPM on the free-entry equilibrium number of firms when the entry decision is taken upstream, downstream, or jointly by the supply hierarchy? What are the effects in terms of consumer surplus and total welfare? Which forces shape these results? Does the free-entry equilibrium number of firms differ from the socially optimal number? What affects entry bias?

To address these issues, we consider an environment where retailers are better informed than manufacturers about market demand and can exert non-contractible demand-enhancing 
effort, typically in the form of marketing and advertising activities. Such asymmetric information framework, which combines elements of adverse selection and moral hazard, is consistent with the main empirical regularities observed in vertically related markets (e.g., Blair and Lafontaine 2005; Lafontaine and Shaw 1999; Lafontaine and Slade 1997). Each manufacturer is in an exclusive relationship with its retailer. This framing is reasonable in a wide range of circumstances, such as the presence of product-specific investments that have to be sunk before production decisions are made. Furthermore, in line with the literature on competing hierarchies under asymmetric information (e.g., Coughlan and Wernerfelt 1989; Katz 1991; Martimort 1996; Martimort and Piccolo 2010), bilateral contracting within a supply hierarchy is secret. This reflects the natural idea that the trading rules specified in a contractual relationship are not observed by competitors, typically because of the possibility of secret renegotiation.

In order to identify the welfare effects of vertical price restraints under an endogenous market structure in a tractable and transparent manner, we focus on a setting where, for any given number of firms, the two legal regimes of laissez-faire and ban on RPM are equivalent from the consumers' point of view (Martimort and Piccolo 2007). This unbiased framework is suitable for an insightful analysis that allows for endogenous entry. The legal regime that brings higher entry increases consumer surplus. The impact of each legal regime in terms of total welfare is the result of the interaction between two effects: the free-entry effect, which captures the welfare impact of a legal regime associated with a change in the number of firms operating in the market, and the vertical-restraints effect, which identifies the welfare impact of that regime for any given number of firms. We find that, in markets where manufacturers take the entry decision, a regime of laissez-faire stimulates entry, which translates into higher consumer surplus. The intuitive reason is that RPM enlarges the set of instruments to which manufacturers can resort to control retailers and to mitigate their informational rents arising from superior information. For any given number of firms, manufacturers obtain higher (expected) profits from RPM, which encourages entry and makes consumers better off. Our analysis suggests that antitrust authorities with a consumer welfare mandate allow RPM in markets where the entry decision takes place upstream. However, a laissez-faire regime leads to a reduction in total welfare. As manufacturers make zero profits in equilibrium, total welfare consists of consumer surplus and the retailers' aggregate profits.

The impact of laissez-faire on total welfare is the result of the trade-off between the freeentry effect and the vertical-restraints effect. On the one hand, laissez-faire generates a positive free-entry effect associated with a higher number of entrants, which leads to higher total welfare. The increase in consumer surplus stemming from more intense competition outweighs the corresponding reduction in the retailers' aggregate profits. On the other hand, for any given number of entrants, laissez-faire allows manufacturers to stifle the retailers' profits, which creates a negative vertical-restraints effect. It turns out that the vertical-restraints effect dominates the free-entry effect. This is because the discontinuous decrease in the retailers' profits associated with RPM for a given number of firms more than compensates the smooth increase in consumer surplus (net of the retailers' profits) from the tougher competition. Hence, our analysis recommends that antitrust authorities equipped with a total welfare standard prohibit RPM in markets where entry is established at the upstream level. 
Results change significantly in markets where retailers decide upon entry. As RPM reduces the retailers' profits, a ban on RPM boosts entry and benefits consumers. Antitrust authorities that merely care about consumer surplus are encouraged to forbid RPM. Our findings are less stark in terms of total welfare. Since the retailers' profits vanish in equilibrium, total welfare consists of consumer surplus and the manufacturers' aggregate profits. The free-entry effect of laissez-faire associated with a lower number of firms is positive, provided that the entry costs are relatively small. This indicates that the consumers' losses from softer competition under laissez-faire are more than compensated by the manufacturers' gains as long as competition is not too weak. The vertical-restraints effect of laissez-faire is unambiguously positive because laissez-faire makes manufacturers better off for any given number of firms. Therefore, when the entry costs are relatively small, the free-entry effect and the vertical-restraints effect move in the same direction, and laissez-faire is total welfare superior. For sufficiently large entry costs, the free-entry effect becomes negative and dominates the positive vertical-restraints effect, which implies that a ban on RPM enhances total welfare.

We also compare the free-entry equilibrium number of firms with the optimal number that a total welfare maximizing planner would select. Under both legal regimes, the classical 'businessstealing effect' à la Mankiw and Whinston (1986) operates, which implies that entry is socially excessive. Notably, we find that the entry bias shrinks with the spread of demand uncertainty. Hence, the presence of asymmetric information alleviates the need for public intervention to regulate entry.

Our work advocates an accurate antitrust analysis of the relationship between vertical price restraints and market structure. The predictions of our model provide further corroboration for the adoption of a rule of reason under which antitrust authorities evaluate RPM agreements according to specific procedures, instead of a per se rule that outlaws this practice tout court. In the antitrust case Leegin Creative Leather Products, Inc., v. PSKS, Inc. (551 US 877, 2007), the US Supreme Court replaced the well-established doctrine of per se unlawfulness of RPM with a rule of reason. Other countries (e.g., New Zealand) traditionally authorize RPM agreements if the social benefits can be shown to outweigh the corresponding social costs. Our analysis can contribute to the definition of practical criteria and protocols to guide antitrust authorities through a comprehensive welfare assessment of vertical restraints.

Related literature. The literature on vertical restraints is fairly extensive. The pioneering contributions of Spengler (1950) and Telser (1960), followed by Mathewson and Winter (1984), identify the beneficial effects of retail price restrictions. In this literature, RPM helps manufacturers to internalize negative vertical and horizontal externalities, typically associated with excessive final prices due to double marginalization and with free-riding in the provision of services. Introducing uncertainty about market demand and retail costs, Rey and Tirole (1986) derive the conditions under which vertical restraints are welfare detrimental because they lead to higher expected prices and lower variance of consumption. In a setting with local shocks on market demand and retail costs, Jullien and Rey (2007) show that RPM leads to more uniform retail prices, which enables manufacturers to detect deviations from a collusive agreement in a more efficient manner and makes collusion more likely to be sustained. Relevant contributions to vertical contracting also consider market environments where manufacturers engage in ex- 
clusive relationships with independent retailers. Gal-Or (1991a) explores the incentives of two competing manufacturer-retailer hierarchies to commit to a specific form of vertical pricing, namely RPM, franchise fee pricing, or linear pricing. Closer to our approach is the analysis of vertical restraints within manufacturer-retailer hierarchies in the presence of asymmetric information. Gal-Or (1991b) finds that, under some relevant circumstances, competing manufacturers prefer to contract with independent retailers rather than form a common agency when retailers are privately informed about marginal costs. Martimort (1996) shows that the choice between exclusive dealing and common agency crucially depends on the severity of the adverse selection problem and on the presence of product complementarity or substitutability. In a setting with successive monopolies where the retailer is privately informed about the state of demand and retail costs, Gal-Or (1991c) compares franchise fee and RPM contracts. Providing the manufacturer with an additional screening instrument, RPM mitigates the distributional and pricing distortions from asymmetric information, which makes consumers unambiguously better off. Blair and Lewis (1994) combine elements of adverse selection and moral hazard in a setting where the retailer is privately informed about demand conditions and can exert promotional effort, which is unobservable by the manufacturer. They show that the optimal contract exhibits some form of RPM and quantity forcing. Extending the analysis of Gal-Or (1991c) and Blair and Lewis (1994), Martimort and Piccolo (2007) compare RPM and quantity forcing in a framework with successive monopolies under adverse selection and moral hazard. A striking result is that the two contractual modes are equivalent from the consumers' perspective when demand is linear and the retailer's cost of effort is quadratic. Resorting to this unbiased example, Kastl et al. (2011) compare the legal regimes of laissez-faire and ban on RPM in a setting where two manufacturer-retailer hierarchies compete in the presence of cross-demand externalities. They find that equilibrium quantities are larger (smaller) under laissez-faire when cross-demand externalities are negative (positive). In the spirit of Kastl et al. (2011), we also adopt the unbiased framework with linear demand and quadratic cost of effort, which allows us to better characterize the welfare effects of vertical price restraints in a framework with free entry under different entry decision modes. In a model with adverse selection and moral hazard, Martimort and Piccolo (2010) unveil the strategic value of quantity forcing agreements.

Our work is also related to the well-established literature about free entry. The seminal contribution of Mankiw and Whinston (1986) characterizes the existence of a business stealing effect that induces excessive entry from a social standpoint in a market for homogeneous goods. The analysis of vertical relationships under an endogenous market structure has been underinvestigated in the literature so far. Allowing for free entry in an oligopolistic industry, Raith (2003) studies the firms' provision of managerial incentives to reduce marginal costs. Ghosh and Morita (2007) consider a successive vertical oligopoly model with a fixed number of downstream firms and a large number of potential entrants in the upstream market. They show that, under some relevant circumstances, the entry level in the free-entry equilibrium is socially insufficient. In a setting with non-exclusive vertical relationships and simultaneous free entry in the upstream and downstream market, Reisinger and Schnitzer (2012) compare linear prices with RPM and two-part tariffs. They show that linear prices can be welfare superior because they stimulate downstream market entry. In our paper, we introduce elements of ad- 
verse selection and moral hazard in a free-entry setting with exclusive dealing and compare the legal regimes of laissez-faire and ban on RPM under different entry decision modes. In an adverse selection model where manufacturers decide upon entry and exclusively deal with retailers privately informed about marginal costs of production, Pagnozzi et al. (2016) find that asymmetric information reduces (increases) the number of brands with linear prices (two-part tariffs) and that linear prices lead to a higher number of brands irrespective of the information structure. Differently from Pagnozzi et al. (2016), we investigate the welfare impact of RPM in a setting that allows for different entry decision modes under adverse selection and moral hazard.

The rest of the paper is organized as follows. Section 3 sets out the formal model. Section 4 considers the complete information benchmark. In the presence of asymmetric information, Section 5 derives the equilibrium features that the legal regimes of laissez-faire and ban on RPM exhibit under different entry decision modes for a given number of firms. Sections 6 and 7 characterize the free-entry equilibrium under the two legal regimes and investigate its welfare properties. Section 8 concludes and discusses possible extensions. The main formal proofs are in the Appendix.

\section{The model}

Environment. We consider a vertically related market where $n \geq 1$ retailers compete by selling a homogeneous good. Each retailer $R_{i}$ is in an exclusive relationship with manufacturer $M_{i}$, where $i \in\{1, \ldots, n\}$. This determines a manufacturer-retailer hierarchy $M_{i}-R_{i}$. The production of every unit of the downstream output $q_{i}$ sold by retailer $R_{i}$ requires one unit of the input supplied by manufacturer $M_{i}$. The inverse demand $p_{i}(\cdot)$ faced by retailer $R_{i}$ is

$$
p_{i}\left(\theta, e_{i}, q_{i}, q_{j}\right)=a-\theta+e_{i}-q_{i}-\sum_{j=1, j \neq i}^{n} q_{j},
$$

where $\theta$ is a common demand shock and $e_{i}$ denotes the demand-enhancing effort performed by retailer $R_{i} \cdot{ }^{1}$ The parameter $\theta$ is uniformly distributed on the compact support $\Theta \triangleq[0, \Delta]$, where $\Delta$ identifies the spread of demand uncertainty. Retailers privately observe the realization of $\theta .^{2}$ The effort variable $e_{i} \in \mathbb{R}_{+}$captures the unobservable (or unverifiable) activities conducted by retailer $R_{i}$, such as investments in advertising and pre-sale services, which stimulate the consumers' willingness to pay. Retailer $R_{i}$ incurs a cost $\psi\left(e_{i}\right)=e_{i}^{2}$ to exert effort $e_{i}{ }^{3}$

\footnotetext{
${ }^{1}$ The demand function in (1) is generated by a representative consumer whose preferences are quasi-linear and represented by the utility function (A6) in the Appendix. This is a direct extension of a commonly used utility function (e.g., Vives 1999). The demand intercept $a$ must be sufficiently large so that production occurs irrespective of the number $n$ of competing firms.

${ }^{2}$ The framework with linear demand and uniformely distributed parameter of adverse selection is fairly popular in the literature on vertical control under asymmetric information (e.g., Gal-Or 1991b, 1999; Kastl et al. 2011; Martimort and Piccolo 2010). Our qualitative results carry over to a more complicated setting that allows for nonlinear demand and nonuniformly distributed shocks on market demand or retail costs, provided that uncertainty is sufficiently small.

${ }^{3}$ As shown below (see Section 5), a setting with linear demand and quadratic cost of effort provides an unbiased framework where the legal regimes of laissez-faire and ban on RPM are equivalent from the consumers' point of view for a given number of firms. Our qualitative results continue to hold with a more general quadratic cost of effort. The effort cost function that we adopt ensures the concavity of the total welfare function with respect to the number of firms (see Section 7).
} 
Production technologies are linear, with marginal costs being normalized to zero without any loss of generality. The decision whether to enter the market is taken either by manufacturers, or by retailers, or by manufacturer-retailer hierarchies. Each firm that decides to enter bears a fixed entry cost $K>0$. The free-entry equilibrium number of firms satisfies the standard zero profit condition (e.g., Mankiw and Whinston 1986; Raith 2003), which varies with the entry decision mode.

Contracts. Vertical contracts between manufacturers and retailers exhibit either quantity forcing $(\mathrm{QF})$ or resale price maintenance (RPM). Under QF, a contract specifies a tariff $t_{i}\left(q_{i}\right)$ paid by retailer $R_{i}$ to manufacturer $M_{i}$, which depends on $R_{i}$ 's quantity $q_{i}$. Under RPM, a contract assumes the form $\left\{t_{i}\left(q_{i}\right), p_{i}\left(q_{i}\right)\right\}$, where $p_{i}(\cdot)$ is the price charged by $R_{i}$ as a function of quantity $q_{i}$. Notably, a RPM arrangement expands the set of instruments at the manufacturer's disposal to control the retailer, because it allows the manufacturer to dictate the final price in the downstream market.

One of the following legal regimes is implemented:

- laissez-faire, under which no restriction is imposed on the type of contracts, and therefore either QF or RPM contracts can be stipulated;

- ban on $R P M$, under which retail price restraints are prohibited, and therefore only QF contracts are available.

Our framework captures in a simple and tractable manner the types of vertical price control regulations that are enforced in practice. In line with the literature on competing hierarchies under asymmetric information (e.g., Coughlan and Wernerfelt 1989; Gal-Or 1999; Kastl et al. 2011; Katz 1991; Martimort 1996; Martimort and Piccolo 2010; Pagnozzi et al. 2016), bilateral contracting within each supply hierarchy $M_{i}-R_{i}$ is secret. The idea is that the members of a supply hierarchy cannot observe the trading terms specified in the contract ruling a competing hierarchy. We invoke the revelation principle (e.g., Myerson 1982) in order to identify the set of incentive feasible allocations. For any output choice made by $R_{j}$, there is no loss of generality in deriving the $M_{i}$ 's best response to $M_{j}$ 's contractual offer within the class of direct incentive compatible mechanisms to characterize pure-strategy equilibria.

Under QF, $M_{i}$ offers $R_{i}$ a direct revelation mechanism

$$
\mathcal{M}_{Q} \triangleq\left\{t_{i}\left(m_{i}\right), q_{i}\left(m_{i}\right)\right\}_{m_{i} \in \Theta},
$$

which determines a tariff $t_{i}(\cdot)$ and a quantity $q_{i}(\cdot)$ contingent on $R_{i}$ 's report $m_{i} \in \Theta$ about the demand shock $\theta$. Under RPM, the direct revelation mechanism is a schedule of the form

$$
\mathcal{M}_{P} \triangleq\left\{t_{i}\left(m_{i}\right), q_{i}\left(m_{i}\right), p_{i}\left(m_{i}\right)\right\}_{m_{i} \in \Theta},
$$

where the retail price $p_{i}(\cdot)$ charged by $R_{i}$ is also specified as a function of $R_{i}$ 's report $m_{i}{ }^{4}$

\footnotetext{
${ }^{4}$ As formally shown by Martimort and Piccolo (2007), our analysis is unaffected if under RPM manufacturers cannot directly control the level of output sold by their retailers. The reason is that, for screening purposes, RPM generates a downward output distortion with respect to the complete information benchmark. Retailers would like to expand production so that the marginal benefit of an additional unit, i.e., the retail price, is equal
} 
These contract menus are incentive compatible, namely they induce $R_{i}$ to report truthfully the demand shock, which implies $m_{i}=\theta$ in equilibrium.

In our setting, contracts are incomplete because $M_{i}$ cannot contract upon either the quantity of $R_{j}$ or any report of $R_{j}$ about the demand shock. This assumption has a solid foundation in the literature (e.g., Gal-Or 1991b, 1992, 1999; Kastl et al. 2011; Martimort 1996; Martimort and Piccolo 2010) and can be justified on several grounds. ${ }^{5}$ For instance, a contract contingent on the sales of competing retailers may be condemned as a collusive practice by antitrust authorities. Alternatively, these sales can be hard to observe or verify because of the lack of proper auditing rights.

Timing and equilibrium concept. The sequence of events unfolds as follows.

1. The social planner determines the legal regime, namely laissez-faire or ban on RPM.

2. Supply hierarchies enter the market and incur a fixed entry cost.

3. A demand shock is realized and privately observed by each retailer.

4. Manufacturers secretly make (take-it-or-leave-it) offers to their retailers. Each offer can be either rejected or accepted. If the offer is rejected, every firm within the supply hierarchy obtains an outside option (normalized to zero). If the offer is accepted, each retailer sends a report about the demand shock to its manufacturer.

5. Retailers provide effort, downstream competition takes place, and contracts are executed.

The solution concept that we adopt is Perfect Bayesian Equilibrium, with the standard 'passive beliefs' refinement. Any retailer that receives an unexpected offer from its manufacturer does not revise the beliefs about the equilibrium strategies of competing retailers. ${ }^{6}$ In our framework, passive beliefs reflect the idea that manufacturers cannot signal to retailers information that they do not possess about rivals, because supply hierarchies are independent and act simultaneously. We look for symmetric pure-strategy equilibria.

\section{Complete information benchmark}

To gain insights on how the impact of each legal regime in terms of entry decisions and market allocations depends on the information structure, we first consider the benchmark scenario where the demand shock is common knowledge. The following remark shows that the equilibrium of the game coincides under the two legal regimes and corresponds to the one under complete information, irrespective of the observability (or verifiability) of effort. ${ }^{7}$

to the marginal cost of effort, as under complete information. This implies that retailers do not have incentives to sell only a fraction of the quantity bought from their manufacturers. Consequently, our results are robust to the lack of verifiability of final output under RPM.

${ }^{5}$ We refer to Martimort (1996) for a thorough discussion of this assumption.

${ }^{6}$ This is in line with the market-by-market bargaining restriction of Hart and Tirole (1990) and with the passive beliefs or pairwise-proofness assumption of McAfee and Schwartz (1994).

${ }^{7}$ The proof is straightforward and therefore omitted. 
Remark 1 If the demand shock $\theta$ is common knowledge, for any given number $n$ of competing hierarchies, under laissez-faire and a ban on RPM the equilibrium exhibits the following features:

$$
\begin{gathered}
q^{*}(n, \theta)=p^{*}(n, \theta)=\frac{2(a-\theta)}{2 n+1} \\
e^{*}(n, \theta)=\frac{q^{*}(n, \theta)}{2}=\frac{a-\theta}{2 n+1} .
\end{gathered}
$$

The free-entry equilibrium number $n^{*}$ of supply hierarchies is the same under the two legal regimes.

As vertical contracting is secret and cannot be used for strategic purposes, each manufacturer removes the double marginalization problem by making its retailer residual claimant for the supply hierarchy's overall profits, which are extracted via the tariff (fixed fee). The retailer provides effort efficiently such that the associated marginal cost equals the marginal benefit, which corresponds to the market sales. Entry decisions and market allocations coincide under $\mathrm{QF}$ and RPM, and therefore the choice of the legal regime is welfare inconsequential.

\section{Asymmetric information}

The presence of asymmetric information generates a vertical externality within each supply hierarchy, which affects entry decisions and market allocations. Even when the retail price can be contracted upon, a manufacturer is not able to disentangle the demand shock from its retailer's effort. For any demand $p_{i}(\cdot)$ in $(1), R_{i}$ has an incentive to claim that a given amount of sales arises from high effort despite low demand. In order to induce truthful revelation, $M_{i}$ must provide $R_{i}$ with some informational rents. The choice between QF and RPM arrangements has an impact on the magnitude of informational rents and on the associated distortions in quantity and effort. Hence, the free-entry equilibrium number of supply hierarchies shall crucially depend on the legal regime in force as well as on the entry decision mode.

\section{Laissez-faire}

Under laissez-faire, the social planner does not impose any restriction on retail price control, which implies that both QF and RPM contracts are allowed. With secret contracting, manufacturers prefer to exploit all possible contracting variables and therefore they opt for RPM, irrespective of the competitors' behavior. This result is formalized in the following remark. ${ }^{8}$

Remark 2 In the laissez-faire regime, the equilibrium exhibits RPM.

Proceeding backwards, we characterize the equilibrium quantity and effort under RPM for a given number of supply hierarchies. As $M_{i}$ indirectly selects the effort level exerted by $R_{i}$ as a function of the demand shock $\theta$, we find from (1) that

$$
e_{i}=p_{i}+\theta-a+q_{i}+\sum_{j=1, j \neq i}^{n} q_{j} .
$$

\footnotetext{
${ }^{8}$ The proof is immediate and therefore omitted.
} 
The profits - i.e., the informational rents - accruing to retailer $R_{i}$ that faces the demand shock $\theta$ and reports $m_{i}$ can be written as

$$
U_{i}(\theta)=\max _{m_{i} \in \Theta}\left\{p_{i}\left(m_{i}\right) q_{i}\left(m_{i}\right)-\psi\left(p_{i}\left(m_{i}\right)+\theta-a+q_{i}\left(m_{i}\right)+\sum_{j=1, j \neq i}^{n} q_{j}(\theta)\right)-t_{i}\left(m_{i}\right)\right\},
$$

where incentive compatibility implies $m_{i}=\theta$ in equilibrium. Using $\psi\left(e_{i}\right)=e_{i}^{2}$, the first-order and second-order conditions for incentive compatibility yield

$$
\dot{U}_{i}(\theta)=-2\left[1+\sum_{j=1, j \neq i}^{n} \dot{q}_{j}(\theta)\right]\left[p_{i}(\theta)+\theta-a+q_{i}(\theta)+\sum_{j=1, j \neq i}^{n} q_{j}(\theta)\right]
$$

and

$$
-\left[1+\sum_{j=1, j \neq i}^{n} \dot{q}_{j}(\theta)\right]\left[\dot{p}_{i}(\theta)+\dot{q}_{i}(\theta)\right] \geq 0 .
$$

The participation constraint for retailer $R_{i}$ is given by

$$
U_{i}(\theta) \geq 0
$$

Under RPM, $M_{i}$ designs a menu $\mathcal{M}_{P}$ that maximizes the expected tariff paid by $R_{i}$. Using $U_{i}(\cdot)$ in (5), $M_{i}^{\prime}$ 's maximization program writes as

$$
\max _{q_{i}(\cdot), p_{i}(\cdot)} \int_{0}^{\Delta}\left[p_{i}(\theta) q_{i}(\theta)-\psi\left(p_{i}(\theta)+\theta-a+q_{i}(\theta)+\sum_{j=1, j \neq i}^{n} q_{j}(\theta)\right)-U_{i}(\theta)\right] f(\theta) d \theta
$$

subject to the first-order and second-order conditions for incentive compatibility (6) and (7), and the participation constraint (8).

We conjecture, and verify ex-post, that in equilibrium

$$
1+\sum_{j=1, j \neq i}^{n} \dot{q}_{j}(\theta)>0 .
$$

Hence, $U_{i}(\cdot)$ decreases with $\theta$ and the participation constraint (8) is binding at the upper bound $\Delta$. Integrating both sides of (6) and using (4) yields

$$
U_{i}(\theta)=\int_{\theta}^{\Delta} 2\left[1+\sum_{j=1, j \neq i}^{n} \dot{q}_{j}(z)\right] e_{i}(z) d z .
$$

As shown in the sequel, in equilibrium the quantity $q_{j}(\cdot)$ decreases with the demand shock $\theta$ — i.e., $\dot{q}_{j}(\cdot)<0$. This implies that, for any given effort $e_{i}(\cdot)$ and quantity $q_{j}(\cdot)$, an increase in the number $n$ of supply hierarchies leads to lower informational rents for retailer $R_{i}$. This is the so-called competing-contracts effect highlighted in Martimort (1996). Tougher competition mitigates the retailer's incentives to exaggerate the demand shock. The reason is that the lower equilibrium market price associated with tougher competition reduces the gains from this manipulation.

Taking the expectation over $\theta$ of $R_{i}$ 's informational rents in (9) and integrating by parts, while neglecting for the time being the second-order condition for incentive compatibility (7), 
$M_{i}$ 's maximization program becomes

$$
\begin{aligned}
\max _{q_{i}(\cdot), p_{i}(\cdot)} \int_{0}^{\Delta}\left\{p_{i}(\theta) q_{i}(\theta)-\psi\left(p_{i}(\theta)+\theta-a+q_{i}(\theta)+\sum_{j=1, j \neq i}^{n} q_{j}(\theta)\right)+\right. \\
\left.-2 h(\theta)\left[1+\sum_{j=1, j \neq i}^{n} \dot{q}_{j}(\theta)\right]\left[p_{i}(\theta)+\theta-a+q_{i}(\theta)+\sum_{j=1, j \neq i}^{n} q_{j}(\theta)\right]\right\} f(\theta) d \theta,
\end{aligned}
$$

where $h(\theta) \triangleq \frac{F(\theta)}{f(\theta)}$ is the (inverse) hazard rate.

As $\psi\left(e_{i}\right)=e_{i}^{2}$, the first-order conditions for $q_{i}(\cdot)$ and $p_{i}(\cdot)$ arising from pointwise optimization entail

$$
q^{P}(n, \theta)=p^{P}(n, \theta)=2 e^{P}(n, \theta)+2 h(\theta)\left[1+(n-1) \dot{q}^{P}(n, \theta)\right] .
$$

An inspection of (2), (3) and (10) reveals that output is produced efficiently for a given effort, but a downward distortion in effort is required in order to curb the retailer's informational rents. Using (4) yields after some manipulation

$$
q^{P}(n, \theta)=\frac{2(a-\theta)}{2 n+1}-2 h(\theta) \frac{1+(n-1) \dot{q}^{P}(n, \theta)}{2 n+1} .
$$

Solving the differential equation (11) (see the Appendix), we obtain the following result.

Lemma 1 Under laissez-faire, for any given number $n$ of supply hierarchies, the equilibrium exhibits the following features:

$$
\begin{gathered}
q^{P}(n, \theta)=p^{P}(n, \theta)=\frac{2 a}{2 n+1}-\frac{4 \theta}{4 n-1} \\
e^{P}(n, \theta)=\frac{q^{P}(n, \theta)}{2}-\theta\left[1+(n-1) \dot{q}^{P}(n, \theta)\right]=\frac{a}{2 n+1}-\frac{5 \theta}{4 n-1} .
\end{gathered}
$$

The equilibrium schedules $q^{P}(\cdot), p^{P}(\cdot)$ and $e^{P}(\cdot)$ in (12) and (13) decrease with $\theta$ and are downward distorted with respect to the complete information levels in (2) and (3) for any $\theta$, except for $\theta=0$ (standard 'no distortion at the top' result). ${ }^{9}$ An increase in the number $n$ of entrants mitigates the downward effort distortion for a given output, because retailers have lower incentives to manipulate their private information about the demand shock.

\section{Ban on RPM}

When RPM is banned, manufacturers can only resort to QF contracts. This implies that retailers are now free to choose the preferred effort level. Using (1), the profits accruing to retailer $R_{i}$ that faces the demand shock $\theta$ and reports $m_{i}$ are given by

$$
U_{i}(\theta)=\max _{m_{i} \in \Theta}\left\{\max _{e_{i} \in \mathbb{R}_{+}}\left\{\left[\theta+e_{i}-q_{i}\left(m_{i}\right)-\sum_{j=1, j \neq i}^{n} q_{j}(\theta)\right] q_{i}\left(m_{i}\right)-\psi\left(e_{i}\right)\right\}-t_{i}\left(m_{i}\right)\right\},
$$

where incentive compatibility implies $m_{i}=\theta$ in equilibrium. As $\psi\left(e_{i}\right)=e_{i}^{2}$, the amount of effort exerted by $R_{i}$ is

$$
e_{i}(\theta)=\frac{q_{i}(\theta)}{2}
$$

\footnotetext{
${ }^{9}$ Note that $q^{P}(\cdot)$ is such that $1+(n-1) \dot{q}^{P}(\theta)>0$, which satisfies the second-order condition for incentive compatibility (7).
} 
As under complete information, $R_{i}$ provides the efficient level of effort for a given output. The first-order and second-order conditions for incentive compatibility give

$$
\dot{U}_{i}(\theta)=-\left[1+\sum_{j=1, j \neq i}^{n} \dot{q}_{j}(\theta)\right] q_{i}(\theta)
$$

and

$$
-\left[1+\sum_{j=1, j \neq i}^{n} \dot{q}_{j}(\theta)\right] \dot{q}_{i}(\theta) \geq 0 .
$$

Under $\mathrm{QF}$, the contract that $M_{i}$ offers $R_{i}$ is a menu $\mathcal{M}_{Q}$ that maximizes the expected tariff paid by $R_{i}$. Using $U_{i}(\cdot)$ in (14), $M_{i}$ 's maximization program is

$$
\max _{q_{i}(\cdot)} \int_{0}^{\Delta}\left[p_{i}\left(\theta, e_{i}(\theta), q_{i}(\theta), q_{j}(\theta)\right) q_{i}(\theta)-\psi\left(e_{i}(\theta)\right)-U_{i}(\theta)\right] f(\theta) d \theta
$$

subject to the effort level in (15), the first-order and second-order conditions for incentive compatibility (16) and (17), and the participation constraint (8).

Once again, we conjecture, and verify ex-post, that

$$
1+\sum_{j=1, j \neq i}^{n} \dot{q}_{j}(\theta)>0
$$

in equilibrium. Hence, $U_{i}(\cdot)$ decreases with $\theta$ and the participation constraint (8) is binding at the upper bound $\Delta$. Integrating both sides of (16) yields

$$
U_{i}(\theta)=\int_{\theta}^{\Delta}\left[1+\sum_{j=1, j \neq i}^{n} \dot{q}_{j}(z)\right] q_{i}(z) d z
$$

It follows from (15) that the informational rents in (18) appropriated by retailers under a ban on RPM follow the same rule as the informational rents in (9) under laissez-faire.

Taking the expectation over $\theta$ of $R_{i}$ 's informational rents in (18) and integrating by parts, while neglecting for the time being the second-order condition for incentive compatibility (17), $M_{i}$ 's maximization program reduces to

$$
\max _{q_{i}(\cdot)} \int_{0}^{\Delta}\left\{p_{i}\left(\theta, e_{i}(\theta), q_{i}(\theta), q_{j}(\theta)\right) q_{i}(\theta)-\psi\left(e_{i}(\theta)\right)-h(\theta)\left[1+\sum_{j=1, j \neq i}^{n} \dot{q}_{j}(\theta)\right] q_{i}(\theta)\right\} f(\theta) d \theta
$$

subject to (15).

As $\psi\left(e_{i}\right)=e_{i}^{2}$, the first-order condition for $q_{i}(\cdot)$ arising from pointwise optimization yields

$$
q^{Q}(n, \theta)=\frac{2(a-\theta)}{2 n+1}-2 h(\theta) \frac{1+(n-1) \dot{q}^{Q}(n, \theta)}{2 n+1} .
$$

Solving the differential equation (19) (see the Appendix), we obtain the following result.

Lemma 2 Under a ban on RPM, for any given number $n$ of supply hierarchies, the equilibrium exhibits the following features:

$$
\begin{aligned}
& q^{Q}(n, \theta)=\frac{2 a}{2 n+1}-\frac{4 \theta}{4 n-1} \\
& p^{Q}(n, \theta)=\frac{2 a}{2 n+1}-\frac{\theta}{4 n-1}
\end{aligned}
$$




$$
e^{Q}(n, \theta)=\frac{q^{Q}(n, \theta)}{2}=\frac{a}{2 n+1}-\frac{2 \theta}{4 n-1} .
$$

A comparison between (12) and (20) indicates that RPM and QF agreements generate the same downstream output. ${ }^{10}$

As shown by Martimort and Piccolo (2007) in a framework with successive monopolies, a QF contract induces the retailer to provide the efficient level of effort, which inflates demand and exacerbates the retailer's incentives to manipulate its private information about demand. In order to extract the retailer's informational rents, the manufacturer prefers to distort a QF contract to a further extent with respect to a RPM contract. These two effects exactly cancel out in a setting with linear demand and quadratic cost of effort. Consequently, RPM and QF agreements lead to the same downstream output for any given number of supply hierarchies. This unbiased framework allows us to provide useful insights into the effects of each legal regime in the presence of endogenous entry.

As (21) and (22) reveal, a QF contract yields a distortion from the efficient pricing rule, which is alleviated by a larger number of supply hierarchies, but induces the efficient level of effort for a given output.

\section{$5 \quad$ Free-entry equilibrium and consumer surplus}

Equipped with the results of the previous section, we are now in a position to characterize the equilibrium number of supply hierarchies that enter the market. We denote the legal regime by $l \in\{P, Q\}$, where $P$ identifies laissez-faire (which induces RPM) and $Q$ represents a ban on RPM (which induces $\mathrm{QF}$ ). The equilibrium number of entrants satisfies the standard zero profit condition, where we ignore the integer constraint for expositional purposes in line with the main literature (e.g., Ghosh and Morita 2007; Mankiw and Whinston 1986; Pagnozzi et al. 2016; Raith 2003; Reisinger and Schnitzer 2012).

We first consider the case where the entry decision is taken upstream. Defining by $\mathbb{E}_{\theta}\left[\Pi^{l}(\cdot)\right]$ the manufacturer's expected profits gross of the fixed entry cost $K$ under the legal regime $l \in\{P, Q\}$, the free-entry equilibrium number $n_{M}^{l}$ of competing hierarchies is such that

$$
\mathbb{E}_{\theta}\left[\Pi^{l}\left(n_{M}^{l}, \theta\right)\right]-K=0
$$

We find the following result.

Proposition 1 When the entry decision is taken by manufacturers, the free-entry equilibrium number of supply hierarchies is larger under laissez-faire than under a ban on RPM-i.e., $n_{M}^{P}>n_{M}^{Q}$. Then, laissez-faire increases expected consumer surplus with respect to a ban on $R P M$.

Panel (a) in Figure 1 illustrates the free-entry equilibrium when manufacturers decide upon entry. For any given number of entrants, a laissez-faire regime generates higher expected profits for each manufacturer compared to a ban on RPM. This is because the manufacturer benefits

\footnotetext{
${ }^{10}$ Note that, as under RPM, $q^{Q}(\cdot)$ is such that $1+(n-1) \dot{q}_{j}(\theta)>0$, which satisfies the second-order condition for incentive compatibility (17).
} 


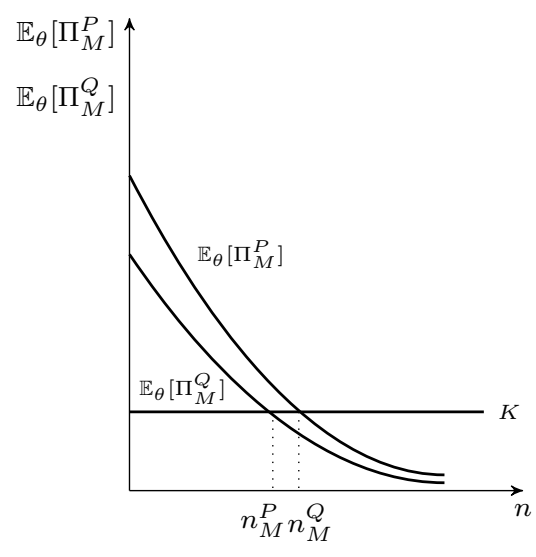

(a) Manufacturers

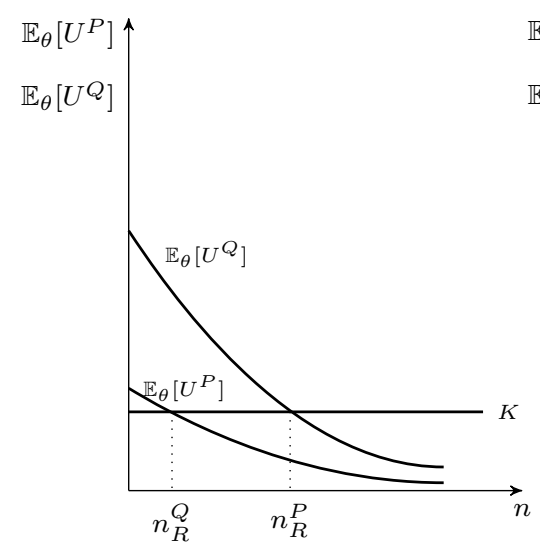

(b) Retailers

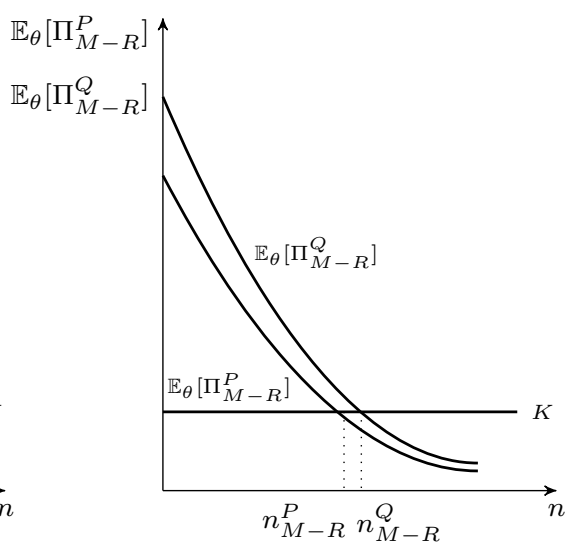

(c) Manufacturer-retailer hierarchies

Figure 1: Free-entry equilibrium under different entry decision modes

from the more extensive control over its retailer achievable through a RPM contract. As the manufacturer's profits decrease with the number of entrants irrespective of the legal regime, competition is more severe under laissez-faire, which makes consumers better off. Hence, according to this result, antitrust authorities with a consumer welfare standard should be advised to allow retail price restrictions in markets where the entry decision is taken at the upstream level.

We now turn to the case where entry is chosen downstream. Defining by $\mathbb{E}_{\theta}\left[U^{l}(\cdot)\right]$ the retailer's expected profits gross of the fixed entry cost $K$ under the legal regime $l \in\{P, Q\}$, the free-entry equilibrium number $n_{R}^{l}$ of supply hierarchies satisfies the zero profit condition

$$
\mathbb{E}_{\theta}\left[U^{l}\left(n_{R}^{l}, \theta\right)\right]-K=0
$$

This yields the following result.

Proposition 2 When the entry decision is taken by retailers, the free-entry equilibrium number of supply hierarchies is larger under a ban on RPM than under laissez-faire - i.e., $n_{R}^{Q}>n_{R}^{P}$. Then, a ban on RPM increases expected consumer surplus with respect to laissez-faire.

Panel (b) in Figure 1 illustrates the free-entry equilibrium when retailers decide upon entry. To understand the rationale for this result, note from (9) and (18) that, for any given number of entrants (and corresponding output), a ban on RPM makes entry more attractive for retailers than laissez-faire because RPM allows each manufacturer to distort the retailer's effort downwards in order to limit the retailer's informational rents. Given that the retailer's profits decline with the number of entrants irrespective of the legal regime, a ban on RPM intensifies competition. Hence, according to this result, antitrust authorities with a consumer welfare mandate should prohibit retail price restrictions in markets where the entry choice is established at the downstream level.

Finally, we consider the case where the entry decision is jointly taken by each manufacturerretailer hierarchy. We define by $\mathbb{E}_{\theta}\left[\Pi_{M-R}^{l}(\cdot)\right]$ the supply hierarchy's expected aggregate profits (computed as the sum of the manufacturer's and retailer's profits) gross of the fixed entry cost 
$K$ under the legal regime $l \in\{P, Q\}$. Then, the free-entry equilibrium number $n_{M-R}^{l}$ of supply hierarchies satisfies the zero profit condition

$$
\mathbb{E}_{\theta}\left[\Pi_{M-R}^{l}\left(n_{M-R}^{l}, \theta\right)\right]-K=0 .
$$

We find the following result.

Proposition 3 When the entry decision is taken by supply hierarchies, the free-entry equilibrium number of supply hierarchies is larger under a ban on RPM than under laissez-faire i.e., $n_{M-R}^{Q}>n_{M-R}^{P}$. Then, a ban on RPM increases expected consumer surplus (and expected total welfare) with respect to laissez-faire.

Panel (c) in Figure 1 illustrates the free-entry equilibrium when manufacturer-retailer hierarchies decide upon entry. We know from the discussion after Propositions 1 and 2 that, for any given number of entrants, the manufacturer's profits are higher under laissez-faire than under a ban on RPM but the converse holds for the retailer's profits. The latter effect on the supply hierarchy's aggregate profits outweighs the former effect, and therefore the supply hierarchy jointly benefits from a ban on RPM, keeping fixed the number of entrants. To appreciate the rationale for this result, recall from our previous analysis that a QF contract induces the retailer to exert the efficient level of effort that maximizes the supply hierarchy's overall profits. Since the retailer's informational rents constitute a mere internal transfer within the supply hierarchy, the efficient effort provision under QF induces a demand expansion that makes the supply hierarchy jointly better off. Hence, as Proposition 3 reveals, competition is tougher under a ban on RPM when the entry decision is taken at the supply hierarchy's level. Given that the supply hierarchy's aggregate profits vanish in equilibrium, expected consumer surplus coincides with expected total welfare, and a ban on RPM benefits consumers and society as a whole.

\section{Total welfare}

We now characterize the total welfare effects of each legal regime in the free-entry equilibrium. We start with the case where entry is determined at the upstream level.

Proposition 4 When the entry decision is taken by manufacturers, a ban on RPM increases expected total welfare with respect to laissez-faire.

We know from Proposition 1 that, in markets where the entry decision takes place upstream, antitrust authorities seeking to maximize consumer welfare should enforce a laissez-faire regime. As Proposition 4 indicates, things change significantly when a total welfare objective is pursued, and antitrust authorities are encouraged to prohibit RPM. To understand the rationale for this result, recall that, when the entry decision is taken at the upstream level, the zero profit condition entails

$$
\mathbb{E}_{\theta}\left[\Pi_{M}^{l}\left(n_{M}^{l}, \theta\right)\right]-K=0
$$

under the legal regime $l \in\{P, Q\}$. Expected total welfare $\mathbb{E}_{\theta}\left[T W_{M}^{l}\left(n_{M}^{l}, \theta\right)\right]$ consists of the sum of expected consumer surplus $\mathbb{E}_{\theta}\left[C S\left(n_{M}^{l}, \theta\right)\right]$ and the retailers' expected aggregate profits 
$n_{M}^{l} \mathbb{E}_{\theta}\left[U^{l}\left(n_{M}^{l}, \theta\right)\right]$. Then, we have

$$
\mathbb{E}_{\theta}\left[T W_{M}^{l}\left(n_{M}^{l}, \theta\right)\right] \triangleq \mathbb{E}_{\theta}\left[C S\left(n_{M}^{l}, \theta\right)\right]+n_{M}^{l} \mathbb{E}_{\theta}\left[U^{l}\left(n_{M}^{l}, \theta\right)\right] .
$$

As formally shown in the proof of Proposition 4, the total welfare comparisons between the two legal regimes hold regardless of the difference in the equilibrium number of entrants. To gain insights, it is helpful to consider now the situation where this difference is relatively small, which occurs as long as the spread of demand uncertainty $\Delta$ is not too large. Applying a first-order Taylor approximation to expected total welfare $\mathbb{E}_{\theta}\left[T W_{M}^{Q}\left(n_{M}^{Q}, \theta\right)\right]$ under a ban on RPM yields

$$
\begin{gathered}
\mathbb{E}_{\theta}\left[T W_{M}^{Q}\left(n_{M}^{Q}, \theta\right)\right] \approx \mathbb{E}_{\theta}\left[C S\left(n_{M}^{P}, \theta\right)\right]+\left.\left(n_{M}^{Q}-n_{M}^{P}\right) \frac{\partial \mathbb{E}_{\theta}[C S(n, \theta)]}{\partial n}\right|_{n=n_{M}^{P}}+ \\
+n_{M}^{P} \mathbb{E}_{\theta}\left[U^{Q}\left(n_{M}^{P}, \theta\right)\right]+\left.\left(n_{M}^{Q}-n_{M}^{P}\right) \frac{\partial n \mathbb{E}_{\theta}\left[U^{Q}(n, \theta)\right]}{\partial n}\right|_{n=n_{M}^{P}} .
\end{gathered}
$$

Using (23) and (24), the difference in expected total welfare between the two legal regimes can be (approximately) written as

$$
\begin{gathered}
\mathbb{E}_{\theta}\left[T W_{M}^{P}\left(n_{M}^{P}, \theta\right)\right]-\mathbb{E}_{\theta}\left[T W_{M}^{Q}\left(n_{M}^{Q}, \theta\right)\right] \\
\approx \underbrace{\left.n_{M}^{P}-n_{M}^{Q}\right)\left(\left.\frac{\partial \mathbb{E}_{\theta}[C S(n, \theta)]}{\partial n}\right|_{n=n_{M}^{P}}+\left.\frac{\partial n \mathbb{E}_{\theta}\left[U^{Q}(n, \theta)\right]}{\partial n}\right|_{n=n_{M}^{P}}\right)}_{\text {free-entry effect (+) }}+ \\
+\underbrace{n_{M}^{P} \mathbb{E}_{\theta}\left[U^{P}\left(n_{M}^{P}, \theta\right)-U^{Q}\left(n_{M}^{P}, \theta\right)\right]}_{\text {vertical-restraints effect (-) }} .
\end{gathered}
$$

This is the result of two opposite effects. On the one hand, a larger number of entrants under laissez-faire $\left(n_{M}^{P}>n_{M}^{Q}\right)$ generates a positive free-entry effect, which leads to higher total welfare. The increase in consumer surplus associated with tougher competition exceeds the corresponding reduction in the retailers' aggregate profits. On the other hand, we know from the previous analysis that, for any given number of entrants, a QF contract provides retailers with higher informational rents. Then, laissez-faire creates a negative vertical-restraints effect, which reduces total welfare. As formally shown in the proof of Proposition 4, the vertical-restraints effect dominates the free-entry effect. A switch from laissez-faire to a ban on RPM entails a discontinuous rise in the retailers' aggregate profits that outweighs the smooth fall in consumer surplus (net of the retailers' aggregate profits). Then, a ban on RPM is total welfare superior.

We now turn to the case where entry is determined at the downstream level. This yields the following result.

Proposition 5 When the entry decision is taken by retailers, there exists a threshold $\widetilde{K}>0$ for the fixed entry cost $K$ such that for $K<\widetilde{K}$ laissez-faire increases expected total welfare with respect to a ban on RPM. The converse holds for $K>\bar{K}$, where $\bar{K}>\widetilde{K}$.

Recall from Proposition 2 that a ban on RPM encourages downstream entry and makes consumers definitely better off. Things can substantially differ in terms of total welfare. When 
the entry decision is taken downstream, the zero profit condition entails

$$
\mathbb{E}_{\theta}\left[U^{l}\left(n_{R}^{l}, \theta\right)\right]-K=0
$$

under the legal regime $l \in\{P, Q\}$. Expected total welfare $\mathbb{E}_{\theta}\left[T W_{R}^{l}\left(n_{R}^{l}, \theta\right)\right]$ consists of the sum of expected consumer surplus $\mathbb{E}_{\theta}\left[C S\left(n_{R}^{l}, \theta\right)\right]$ and the manufacturers' expected aggregate profits $n_{R}^{l} \mathbb{E}_{\theta}\left[\Pi_{M}^{l}\left(n_{R}^{l}, \theta\right)\right]$. Then, we have

$$
\mathbb{E}_{\theta}\left[T W_{R}^{l}\left(n_{R}^{l}, \theta\right)\right] \triangleq \mathbb{E}_{\theta}\left[C S\left(n_{R}^{l}, \theta\right)\right]+n_{R}^{l} \mathbb{E}_{\theta}\left[\Pi_{M}^{l}\left(n_{R}^{l}, \theta\right)\right] .
$$

As formally shown in the proof of Proposition 5, the total welfare comparisons between the two legal regimes hold regardless of the difference in the equilibrium number of entrants. To gain insights, as for the case of entry decision at the upstream level, it is helpful to consider now the situation where this difference is relatively small, which occurs as long as the spread of demand uncertainty $\Delta$ is not too large. Applying a first-order Taylor approximation to expected total welfare $\mathbb{E}_{\theta}\left[T W_{R}^{Q}\left(n_{R}^{Q}, \theta\right)\right]$ under a ban on RPM yields

$$
\begin{gathered}
\mathbb{E}_{\theta}\left[T W_{R}^{Q}\left(n_{R}^{Q}, \theta\right)\right] \approx \mathbb{E}_{\theta}\left[C S\left(n_{R}^{P}, \theta\right)\right]+\left.\left(n_{R}^{Q}-n_{R}^{P}\right) \frac{\partial \mathbb{E}_{\theta}[C S(n, \theta)]}{\partial n}\right|_{n=n_{R}^{P}}+ \\
+n_{R}^{P} \mathbb{E}_{\theta}\left[\Pi_{M}^{Q}\left(n_{R}^{P}, \theta\right)\right]+\left.\left(n_{R}^{Q}-n_{R}^{P}\right) \frac{\partial n \mathbb{E}_{\theta}\left[\Pi_{M}^{Q}(n, \theta)\right]}{\partial n}\right|_{n=n_{R}^{P}} .
\end{gathered}
$$

Using (26) and (27), the difference in expected total welfare between the two legal regimes can be (approximately) written as

$$
\begin{gathered}
\mathbb{E}_{\theta}\left[T W_{R}^{P}\left(n_{R}^{P}, \theta\right)\right]-\mathbb{E}_{\theta}\left[T W_{R}^{Q}\left(n_{R}^{Q}, \theta\right)\right] \\
\approx \underbrace{\left(n_{R}^{P}-n_{R}^{Q}\right)\left(\left.\frac{\partial \mathbb{E}_{\theta}[C S(n, \theta)]}{\partial n}\right|_{n=n_{R}^{P}}+\left.\frac{\partial n \mathbb{E}_{\theta}\left[\Pi_{M}^{Q}(n, \theta)\right]}{\partial n}\right|_{n=n_{R}^{P}}\right)}_{\text {free-entry effect (+,-) }}+ \\
+\underbrace{n_{R}^{P} \mathbb{E}_{\theta}\left[\Pi_{M}^{P}\left(n_{R}^{P}, \theta\right)-\Pi_{M}^{Q}\left(n_{R}^{P}, \theta\right)\right]}_{\text {vertical-restraints effect (+) }} .
\end{gathered}
$$

A lower number of entrants under laissez-faire $\left(n_{R}^{P}<n_{R}^{Q}\right)$ reduces consumer surplus but improves the manufacturers' aggregate profits. The free-entry effect of laissez-faire is now ambiguous. As shown in the proof of Proposition 5, there exists a threshold $\widehat{K}$ for the fixed entry cost such that for $K<\widehat{K}$ the negative impact of softer competition on consumer surplus is more than compensated by the corresponding positive impact on the manufacturers' aggregate profits, and therefore the free-entry effect is positive. The idea is that, when entry costs are sufficiently small to ensure some degree of competition even under laissez-faire, the consumers' losses from softer competition compared to a ban on RPM are lower than the manufacturers' aggregate gains. The vertical-restraints effect of laissez-faire is positive because manufacturers benefit from imposing price restrictions on their retailers. For $K<\widehat{K}$, the free-entry effect and the vertical-restraints effect go in the same direction, and the laissez-faire regime is unambiguously total welfare superior. As Proposition 5 reveals, laissez-faire still enhances total welfare if $K<\widetilde{K}$, where 
$\widetilde{K}>\widehat{K}$. For larger entry costs, things become more convoluted. If entry costs are sufficient large - i.e., $K>\bar{K}$, where $\bar{K}>\widetilde{K}$ - the free-entry effect of laissez-faire becomes negative and dominates the positive vertical-restraints effect. Therefore, a ban on RPM is socially preferable because the associated tougher competition is more valuable.

Differently from the case where the entry decision takes place upstream, the free-entry effect may outweigh the vertical-restraints effect when entry is established downstream. To understand why, it helpful to realize that, for any given number of entrants, the rise in the retailers' aggregate profits from a ban on RPM exceeds the rise in the manufacturers' aggregate profits from laissez-faire, and therefore the vertical-restraints effect is less pronounced when the entry decision occurs downstream. This is because the manufacturers' gains from laissez-faire are mitigated by the downward effort distortion that depresses consumer demand.

It is worth comparing the equilibrium number of firms under free entry with the optimal number that a total welfare maximizing planner would choose.

Proposition 6 When the entry decision is taken either by manufacturers or by supply hierarchies, socially excessive entry occurs under both legal regimes - i.e., $n_{M}^{l}>n_{T W}^{l}$ and $n_{M-R}^{l}>n_{T W}^{l}$, where $l \in\{P, Q\}$. Excessive entry declines with the spread of demand uncertainty - i.e., $n_{M}^{l}-n_{T W}^{l}$ and $n_{M-R}^{l}-n_{T W}^{l}$ decrease with $\Delta$.

The classical business-stealing effect à la Mankiw and Whinston (1986) implies that a firm's evaluation of its entry exceeds the social desirability of entry. The entrant does not internalize the total welfare loss from the output contraction by all existing firms. Then, we find that entry is higher than the socially optimal level when the entry decision is taken either by manufacturers or by supply hierarchies. Remarkably, a larger spread of demand uncertainty $\Delta$ mitigates the magnitude of the entry bias.

To gain insights, note that a larger $\Delta$ reduces consumer demand (in expectation) and leads to lower profits for each manufacturer and supply hierarchy, which translates into a lower number of entrants under both legal regimes. As a larger $\Delta$ reduces total welfare, the social planner is induced to increase the number of firms. Hence, socially excessive entry declines with $\Delta$. This result suggests that the need for entry regulation is mitigated by asymmetric information. Intuitively, entry may be insufficient from a social standpoint when the entry decision is taken downstream, especially for small values of $\Delta$ that correspond to low profits for retailers.

\section{Concluding remarks}

Endogenizing the market structure sheds new light on the analysis of the welfare effects of vertical price restraints. In this paper, we compare the legal regimes of laissez-faire and ban on RPM in a setting where the market structure is endogenously determined by free entry. We characterize the free-entry equilibrium and its welfare properties under different entry decision modes. In markets where the entry decision is established upstream, a regime of laissez-faire stimulates entry and increases consumer surplus, but total welfare is higher under a ban on RPM. Conversely, in markets where the entry decision is made downstream, a ban on RPM favors entry and makes consumers better off, but laissez-faire can be total welfare superior. We 
also find that entry is excessive from a social standpoint irrespective of the legal regime when the entry is decided either by manufacturers or by supply hierarchies. Notably, the magnitude of the entry bias declines with the spread of demand uncertainty.

Despite the stylized formulation for expositional purposes, our results can be generalized in some directions. In line with the literature on strategic delegation (e.g., Bonanno and Vickers 1988; Vickers 1985), we consider a setting where each manufacturer only deals with one retailer. The predictions of our model naturally carry over to markets where a manufacturer resorts to multiple retailers, provided that exclusive territory clauses allow a single retailer to operate in a certain area (e.g., Rey and Stiglitz 1995). It is also interesting to consider the possibility that each retailer is supplied by multiple manufacturers. Martimort (1996) shows that, under some relevant circumstances, principals prefer to engage in exclusive relationships with their agents rather than contract with a common agent when goods are substitutes. Therefore, our results are robust to a setting that allows for common agency.

Throughout the analysis, we consider promotional activities exerted by retailers to expand their demand, as systematically documented by the empirical literature (e.g., Bonnet and Dubois 2010; Bonnet et al. 2013). A related aspect that deserves some attention is the existence of cross-demand externalities. The idea is that a retailer's effort may affect not only its demand but also the rivals' demand. Such externalities can be either positive, as in the case of presale services and general advertising (e.g., Mathewson and Winter 1984), or negative, as in the case of production of indivisible services bundled with the final product. Kastl et al. (2011) show that, in a framework with two competing supply hierarchies, laissez-faire leads to higher quantities and increases consumer surplus if cross-demand externalities are negative. When the entry decision is taken upstream, we conjecture that the free-entry equilibrium number of supply hierarchies under laissez-faire shall be higher to a further extent with respect to a ban on RPM, because laissez-faire mitigates the profit-detrimental effect of negative externalities (Kastl et al. 2011). Then, our result of higher entry under laissez-faire should be reinforced in the presence of negative externalities.

Given that aggregate output typically increases with the number of firms, consumer surplus shall be higher under laissez-faire, consistently with our analysis. When the entry decision is taken downstream, negative externalities may exhibit a stronger negative impact on the freeentry equilibrium number of supply hierarchies under a ban on RPM, where retailers exert a higher amount of effort, ceteris paribus. Therefore, we expect that our results of higher entry and consumer surplus under a ban on RPM shall still be valid, provided that negative externalities are not too pronounced. By the same token, this analysis can be extended to the case of positive cross-demand externalities.

Notwithstanding that a more sophisticated setting could accommodate further effects, the principles behind our results are fairly general. The predictions of our model lend themselves to empirical validation and provide potentially significant antitrust policy implications about vertical price control. 


\section{Appendix}

Proof of Lemma 1. The solution to the differential equation (11) is given by

$$
q^{P}(n, \theta)=k e^{-\int_{0}^{\theta} \frac{2 n+1}{2(n-1) z_{1}} d z_{1}}+\int_{0}^{\theta} e^{-\int_{z_{2}}^{\theta} \frac{2 n+1}{2(n-1) z_{1}} d z_{1}} \frac{a-2 z_{2}}{(n-1) z_{2}} d z_{2} .
$$

It follows from

$$
e^{-\int_{0}^{\theta} \frac{2 n+1}{2(n-1) z_{1}} d z_{1}}=e^{-\left.\frac{2 n+1}{2(n-1)} \ln z_{1}\right|_{0} ^{\theta}}=e^{-\infty} \rightarrow 0
$$

that

$$
q^{P}(n, \theta)=\int_{0}^{\theta} e^{-\frac{2 n+1}{2(n-1)}\left(\ln \theta-\ln z_{2}\right)} \frac{a-2 z_{2}}{(n-1) z_{2}} d z_{2} .
$$

As

$$
e^{-\frac{2 n+1}{2(n-1)}\left(\ln \theta-\ln z_{2}\right)}=\frac{z_{2}^{\frac{2 n+1}{2(n-1)}}}{\theta^{\frac{2 n+1}{2(n-1)}}},
$$

we have

$$
q^{P}(n, \theta)=\frac{1}{(n-1) \theta^{\frac{2 n+1}{2(n-1)}}} \int_{0}^{\theta} z_{2}^{\frac{2 n+1}{2(n-1)}} \frac{a-2 z_{2}}{z_{2}} d z_{2} .
$$

Standard calculations show that

$$
\begin{aligned}
\int_{0}^{\theta} z_{2}^{\frac{2 n+1}{2(n-1)}} \frac{a-2 z_{2}}{z_{2}} d z_{2} & =a \int_{0}^{\theta} z_{2}^{\frac{2 n+1}{2(n-1)}-1} d z_{2}-2 \int_{0}^{\theta} z_{2}^{\frac{2 n+1}{2(n-1)}} d z_{2} \\
& =\left.\frac{a}{\frac{2 n+1}{2(n-1)}} z_{2}^{\frac{2 n+1}{2(n-1)}}\right|_{0} ^{\theta}-\left.\frac{2}{\frac{2 n+1}{2(n-1)}+1} z_{2}^{\frac{2 n+1}{2(n-1)}+1}\right|_{0} ^{\theta} \\
& =a \frac{\theta^{\frac{2 n+1}{2(n-1)}}}{\frac{2 n+1}{2(n-1)}}-2 \frac{\theta^{\frac{2 n+1}{2(n-1)}+1}}{\frac{2 n+1}{2(n-1)}+1}
\end{aligned}
$$

Then, we find after some manipulation that

$$
q^{P}(n, \theta)=\frac{2 a}{2 n+1}-\frac{4 \theta}{4 n-1} .
$$

It follows from (4) and (10) that

$$
p^{P}(n, \theta)=q^{P}(n, \theta)=\frac{2 a}{2 n+1}-\frac{4 \theta}{4 n-1}
$$

and

$$
e^{P}(n, \theta)=\frac{a}{2 n+1}-\frac{5 \theta}{4 n-1} .
$$

Proof of Lemma 2. As (11) coincides with (19), it directly follows from the proof of Lemma 1 that

$$
q^{Q}(n, \theta)=\frac{2 a}{2 n+1}-\frac{4 \theta}{4 n-1} .
$$

Moreover, we find from (1) and (15) that

$$
p^{Q}(n, \theta)=\frac{2 a}{2 n+1}-\frac{\theta}{4 n-1}
$$


and

$$
e^{Q}(n, \theta)=\frac{q^{Q}(n, \theta)}{2}=\frac{a}{2 n+1}-\frac{2 \theta}{4 n-1}
$$

Proof of Proposition 1. First, we consider the regime of laissez-faire. For any given number $n$ of supply hierarchies, the manufacturer's expected profits are

$$
\mathbb{E}_{\theta}\left[\Pi^{P}(n, \theta)\right]=\mathbb{E}_{\theta}\left[p\left(\theta, e^{P}(n, \theta), q^{P}(n, \theta)\right) q^{P}(n, \theta)-\psi\left(e^{P}(n, \theta)\right)-U^{P}(n, \theta)\right] .
$$

Using $\psi(e)=e^{2}$ and the expression for $U^{P}(\cdot)$ in (9) yields

$$
\begin{aligned}
\mathbb{E}_{\theta}\left[\Pi^{P}(n, \theta)\right] & =\mathbb{E}_{\theta}\left[p\left(\theta, e^{P}(n, \theta), q^{P}(n, \theta)\right) q^{P}(n, \theta)-\left(e^{P}(n, \theta)\right)^{2}+\right. \\
& \left.-2 h(\theta)\left(1+(n-1) \dot{q}^{P}(n, \theta)\right) e^{P}(n, \theta)\right] .
\end{aligned}
$$

It follows from the first-order condition (10) that

$$
\left(e^{P}(n, \theta)\right)^{2}+2 h(\theta)\left(1+(n-1) \dot{q}^{P}(n, \theta)\right) e^{P}(n, \theta)=q^{P}(n, \theta) e^{P}(n, \theta)-\left(e^{P}(n, \theta)\right)^{2} .
$$

As $q^{P}(\cdot)=p^{P}(\cdot)$, we obtain that

$$
\left.\mathbb{E}_{\theta}\left[\Pi^{P}(n, \theta)\right]=\mathbb{E}_{\theta}\left[q^{P}(n, \theta)\right)^{2}-q^{P}(n, \theta) e^{P}(n, \theta)+\left(e^{P}(n, \theta)\right)^{2}\right] .
$$

Substituting $q^{P}(\cdot)$ in (12) and $e^{P}(\cdot)$ in (13) into (A1) and recalling that $\theta$ is uniformly distributed on $\Theta \triangleq[0, \Delta]$, we find after some manipulation that

$$
\begin{aligned}
\mathbb{E}_{\theta}\left[\Pi^{P}(n, \theta)\right] & \left.=\int_{0}^{\Delta}\left[q^{P}(n, \theta)\right)^{2}-q^{P}(n, \theta) e^{P}(n, \theta)+\left(e^{P}(n, \theta)\right)^{2}\right] f(\theta) d \theta \\
& =\frac{3 a^{2}(4 n-1)^{2}+7 \Delta^{2}(2 n+1)^{2}}{\left(8 n^{2}+2 n-1\right)^{2}}-\frac{6 a \Delta^{2}}{8 n^{2}+2 n-1} .
\end{aligned}
$$

We now turn to a ban on RPM. For any given number $n$ of supply hierarchies, the manufacturer's expected profits are

$$
\mathbb{E}_{\theta}\left[\Pi^{Q}(n, \theta)\right]=\mathbb{E}_{\theta}\left[p\left(\theta, e^{Q}(n, \theta), q^{Q}(n, \theta)\right) q^{Q}(n, \theta)-\psi\left(e^{Q}(n, \theta)\right)-U^{Q}(n, \theta)\right] .
$$

Using $\psi(e)=e^{2}$ and the expression for $U^{Q}(\cdot)$ in (18) yields

$$
\begin{aligned}
\mathbb{E}_{\theta}\left[\Pi^{Q}(n, \theta)\right] & =\mathbb{E}_{\theta}\left[p\left(\theta, e^{Q}(n, \theta), q^{Q}(n, \theta)\right) q^{Q}(n, \theta)-\left(e^{Q}(n, \theta)\right)^{2}+\right. \\
& \left.-h(\theta)\left(1+(n-1) \dot{q}^{Q}(n, \theta)\right) q^{Q}(n, \theta)\right] .
\end{aligned}
$$

It follows from (1) and the first-order condition (19) that

$$
p\left(\theta, e^{Q}(n, \theta), q^{Q}(n, \theta)\right) q^{Q}(n, \theta)-h(\theta)\left(1+(n-1) \dot{q}^{Q}(n, \theta)\right) q^{Q}(n, \theta)=q^{Q}(n, \theta)^{2} .
$$

Then, we obtain that

$$
\mathbb{E}_{\theta}\left[\Pi^{Q}(n, \theta)\right]=\mathbb{E}_{\theta}\left[\left(q^{Q}(n, \theta)\right)^{2}-\left(e^{Q}(n, \theta)\right)^{2}\right] .
$$


Substituting $q^{Q}(\cdot)$ in $(20)$ and $e^{P}(\cdot)$ in (22) into (A3) and recalling that $\theta$ is uniformly distributed on $\Theta \triangleq[0, \Delta]$, we find after some manipulation that

$$
\begin{aligned}
\mathbb{E}_{\theta}\left[\Pi^{Q}(n, \theta)\right] & =\int_{0}^{\Delta}\left[\left(q^{Q}(n, \theta)\right)^{2}-\left(e^{Q}(n, \theta)\right)^{2}\right] f(\theta) d \theta \\
& =\frac{a^{3}(4 n-1)^{3}-(4 a n-a-2 \Delta-4 n \Delta)^{3}}{2 \Delta(2 n+1)\left(8 n^{2}+2 n-1\right)^{2}} .
\end{aligned}
$$

Using (A2) and (A4), we obtain that

$$
\mathbb{E}_{\theta}\left[\Pi^{P}(n, \theta)\right]-\mathbb{E}_{\theta}\left[\Pi^{Q}(n, \theta)\right]=\frac{3 \Delta^{2}}{(4 n-1)^{2}}>0 .
$$

Differentiating $\mathbb{E}_{\theta}\left[\Pi^{P}(n, \theta)\right]$ in $(\mathrm{A} 2)$ and $\mathbb{E}_{\theta}\left[\Pi^{Q}(n, \theta)\right]$ in (A4) with respect to $n$ yields

$$
\frac{\partial \mathbb{E}_{\theta}\left[\Pi^{P}(n, \theta)\right]}{\partial n}<0
$$

and

$$
\frac{\partial \mathbb{E}_{\theta}\left[\Pi^{Q}(n, \theta)\right]}{\partial n}<0 .
$$

This implies that there exist a unique $n_{M}^{P}$ under laissez-faire and a unique $n_{M}^{Q}$ under a ban on RPM such that

$$
\mathbb{E}_{\theta}\left[\Pi^{P}\left(n_{M}^{P}, \theta\right)\right]-K=0
$$

and

$$
\mathbb{E}_{\theta}\left[\Pi^{Q}\left(n_{M}^{Q}, \theta\right)\right]-K=0,
$$

respectively. It follows from (A5) that $n_{M}^{P}>n_{M}^{Q}$.

The demand system in (1) arises from the following utility function

$$
V\left(\theta, q_{i}, q_{j}, y\right)=(a-\theta) \sum_{i=1}^{n} q_{i}+\sum_{i=1}^{n} e_{i} q_{i}-\frac{1}{2} \sum_{i=1}^{n} q_{i}^{2}-\sum_{j=1, j \neq i}^{n} q_{i} q_{j}+y,
$$

where $y$ is the composite good. In a symmetric equilibrium, consumer surplus under the legal regime $l \in\{P, Q\}$ is given by

$$
C S(n, \theta)=\left(\frac{n}{2}+\sum_{i=1}^{n-1} i\right) q^{l}(n, \theta)^{2} .
$$

Using (12) and (20) and recalling that $\theta$ is uniformly distributed on $\Theta \triangleq[0, \Delta]$, we find that, for any given number $n$ of supply hierarchies, expected consumer surplus is the same under both legal regimes and can be written as

$$
\begin{aligned}
\mathbb{E}_{\theta}[C S(n, \theta)] & =\int_{0}^{\Delta}\left(\frac{n}{2}+\sum_{i=1}^{n-1} i\right) q^{l}(n, \theta)^{2} f(\theta) d \theta \\
& =n^{2} \frac{a^{3}(4 n-1)^{3}-(4 a n-a-2 \Delta-4 n \Delta)^{3}}{3\left(8 n^{2}+2 n-1\right)^{2}(2 n+1) \Delta} .
\end{aligned}
$$

Taking the derivative of $\mathbb{E}_{\theta}[C S(n, \theta)]$ with respect to $n$ yields

$$
\frac{\partial \mathbb{E}_{\theta}[C S(n, \theta)]}{\partial n}>0 .
$$


It follows from $n_{M}^{P}>n_{M}^{Q}$ that

$$
\mathbb{E}_{\theta}\left[C S\left(n_{M}^{P}, \theta\right)\right]>\mathbb{E}_{\theta}\left[C S\left(n_{M}^{Q}, \theta\right)\right]
$$

Proof of Proposition 2. First, we consider the regime of laissez-faire. Inserting (12) and (13) into (9) and recalling that $\theta$ is uniformly distributed on $\Theta \triangleq[0, \Delta]$, we find after some manipulation that, for any given number $n$ of supply hierarchies, the retailer's expected profits are given by

$$
\begin{aligned}
\mathbb{E}_{\theta}\left[U^{P}(n, \theta)\right] & =\int_{0}^{\Delta} \int_{\theta}^{\Delta} 2\left[1+(n-1) \dot{q}^{P}(z)\right] e^{P}(z) d z f(\theta) d \theta \\
& =\Delta \frac{3 a(4 n-1)-10 \Delta(2 n+1)}{32 n^{3}-6 n+1}
\end{aligned}
$$

We now turn to a ban on RPM. Inserting (20) into (18) and recalling that $\theta$ is uniformly distributed on $\Theta \triangleq[0, \Delta]$, we find after some manipulation that, for any given number $n$ of supply hierarchies, the retailer's expected profits are

$$
\begin{aligned}
\mathbb{E}_{\theta}\left[U^{Q}(n, \theta)\right] & =\int_{0}^{\Delta} \int_{\theta}^{\Delta}\left[1+(n-1) \dot{q}^{Q}(z)\right] q^{Q}(z) d z f(\theta) d \theta \\
& =\Delta \frac{3 a(4 n-1)-4 \Delta(2 n+1)}{32 n^{3}-6 n+1} .
\end{aligned}
$$

Using (A8) and (A9), we obtain that

$$
\mathbb{E}_{\theta}\left[U^{Q}(n, \theta)\right]-\mathbb{E}_{\theta}\left[U^{P}(n, \theta)\right]=\frac{6 \Delta^{2}}{(4 n-1)^{2}}>0 .
$$

Differentiating $\mathbb{E}_{\theta}\left[U^{P}(n, \theta)\right]$ in $(\mathrm{A} 8)$ and $\mathbb{E}_{\theta}\left[U^{Q}(n, \theta)\right]$ in (A9) with respect to $n$ yields

$$
\frac{\partial \mathbb{E}_{\theta}\left[U^{P}(n, \theta)\right]}{\partial n}<0
$$

and

$$
\frac{\partial \mathbb{E}_{\theta}\left[U^{Q}(n, \theta)\right]}{\partial n}<0 .
$$

This implies that there exist a unique $n_{R}^{P}$ under laissez-faire and a unique $n_{R}^{Q}$ under a ban on RPM such that

$$
\mathbb{E}_{\theta}\left[U^{P}\left(n_{R}^{P}, \theta\right)\right]-K=0
$$

and

$$
\mathbb{E}_{\theta}\left[U^{Q}\left(n_{R}^{Q}, \theta\right)\right]-K=0,
$$

respectively. It follows from $(\mathrm{A} 10)$ that $n_{R}^{Q}>n_{R}^{P}$.

As

$$
\frac{\partial \mathbb{E}_{\theta}[C S(n, \theta)]}{\partial n}>0
$$

(see the end of the proof of Proposition 1), we find that

$$
\mathbb{E}_{\theta}\left[C S\left(n_{R}^{Q}, \theta\right)\right]>\mathbb{E}_{\theta}\left[C S\left(n_{R}^{P}, \theta\right)\right]
$$


Proof of Proposition 3. Under laissez-faire, using (A2) and (A8), we find that, for any given number $n$ of supply hierarchies, the supply hierarchy's expected aggregate profits

$$
\mathbb{E}_{\theta}\left[\Pi_{M-R}^{P}(n, \theta)\right] \triangleq \mathbb{E}_{\theta}\left[\Pi^{P}(n, \theta)\right]+\mathbb{E}_{\theta}\left[U^{P}(n, \theta)\right]
$$

are given by

$$
\mathbb{E}_{\theta}\left[\Pi_{M-R}^{P}(n, \theta)\right]=3 \frac{a^{2}(4 n-1)^{2}-a \Delta[2 n(4 n+1)-1]-\Delta^{2}(2 n+1)^{2}}{\left(8 n^{2}+2 n-1\right)^{2}} .
$$

Under a ban on RPM, using (A4) and (A9), we find that, for any given number $n$ of supply hierarchies, the supply hierarchy's expected aggregate profits

$$
\mathbb{E}_{\theta}\left[\Pi_{M-R}^{Q}(n, \theta)\right] \triangleq \mathbb{E}_{\theta}\left[\Pi_{M}^{Q}(n, \theta)\right]+\mathbb{E}_{\theta}\left[U^{Q}(n, \theta)\right]
$$

become

$$
\mathbb{E}_{\theta}\left[\Pi_{M-R}^{Q}(n, \theta)\right]=3 a \frac{a(4 n-1)-\Delta(2 n+1)}{(2 n+1)^{2}(4 n-1)} .
$$

Using (A11) and (A12), we obtain that

$$
\mathbb{E}_{\theta}\left[\Pi_{M-R}^{Q}(n, \theta)\right]-\mathbb{E}_{\theta}\left[\Pi_{M-R}^{P}(n, \theta)\right]=\frac{3 \Delta^{2}}{(4 n-1)^{2}}>0
$$

Differentiating $\mathbb{E}_{\theta}\left[\Pi_{M-R}^{P}(n, \theta)\right]$ in (A11) and $\mathbb{E}_{\theta}\left[\Pi_{M-R}^{Q}(n, \theta)\right]$ in (A12) with respect to $n$, we find that

$$
\frac{\partial \mathbb{E}_{\theta}\left[\Pi_{M-R}^{P}(n, \theta)\right]}{\partial n}<0
$$

and

$$
\frac{\partial \mathbb{E}_{\theta}\left[\Pi_{M-R}^{Q}(n, \theta)\right]}{\partial n}<0
$$

This implies that there exist a unique $n_{M-R}^{P}$ under laissez-faire and a unique $n_{M-R}^{Q}$ under a ban on RPM such that

$$
\mathbb{E}_{\theta}\left[\Pi_{M-R}^{P}\left(n_{M-R}^{P}, \theta\right)\right]-K=0
$$

and

$$
\mathbb{E}_{\theta}\left[\Pi_{M-R}^{Q}\left(n_{M-R}^{Q}, \theta\right)\right]-K=0,
$$

respectively. It follows from (A13) that $n_{M-R}^{Q}>n_{M-R}^{P}$.

As

$$
\frac{\partial \mathbb{E}_{\theta}[C S(n, \theta)]}{\partial n}>0
$$

(see the end of the proof of Proposition 1), we find that

$$
\mathbb{E}_{\theta}\left[C S\left(n_{M-R}^{Q}, \theta\right)\right]>\mathbb{E}_{\theta}\left[C S\left(n_{M-R}^{P}, \theta\right)\right]
$$

Proof of Proposition 4. Substituting (A7), (A8) and (A9) into (23), we find after some 
manipulation that the difference

$$
\mathbb{E}_{\theta}\left[T W_{M}^{P}\left(n_{M}^{P}, \theta\right)\right]-\mathbb{E}_{\theta}\left[T W_{M}^{Q}\left(n_{M}^{Q}, \theta\right)\right]
$$

in expected total welfare between the two legal regimes is given by

$$
\begin{gathered}
2 a^{2} \frac{\left(n_{M}^{P}-n_{M}^{Q}\right)\left(n_{M}^{P}+n_{M}^{Q}+4 n_{M}^{P} n_{M}^{Q}\right)}{\left(2 n_{M}^{P}+1\right)^{2}\left(2 n_{M}^{Q}+1\right)^{2}}-\frac{a \Delta\left(n_{M}^{P}-n_{M}^{Q}\right)\left[4 n_{M}^{P}\left(8 n_{M}^{Q}-1\right)-4 n_{M}^{Q}+3\right]}{\left(2 n_{M}^{P}+1\right)\left(4 n_{M}^{P}-1\right)\left(2 n_{M}^{Q}+1\right)\left(4 n_{M}^{Q}-1\right)}+ \\
+2 \Delta^{2} \frac{n_{M}^{P}\left(4 n_{M}^{P}-15\right)+6 n_{M}^{Q}+8 n_{M}^{P} n_{M}^{Q}\left(8 n_{M}^{P}+9\right)-4\left(n_{M}^{Q}\right)^{2}\left(52 n_{M}^{P}+1\right)}{3\left(4 n_{M}^{P}-1\right)^{2}\left(4 n_{M}^{Q}-1\right)^{2}}<0,
\end{gathered}
$$

where the inequality follows from $n_{M}^{P}>n_{M}^{Q}$ (see Proposition 1) and the assumptions on the parameters of the model.

We find from (A7) and (A9) that

$$
\left.\frac{\partial \mathbb{E}_{\theta}[C S(n, \theta)]}{\partial n}\right|_{n=n_{M}^{P}}=\frac{4}{3} n_{M}^{P}\left\{\frac{3 a^{2}}{\left(2 n_{M}^{P}+1\right)^{3}}-\frac{6 a \Delta\left(n_{M}^{P}-1\right)}{\left[8\left(n_{M}^{P}\right)^{2}+2 n_{M}^{P}-1\right]^{2}}-\frac{4 \Delta^{2}}{\left(4 n_{M}^{P}-1\right)^{3}}\right\}>0
$$

and

$$
\left.\frac{\partial n \mathbb{E}_{\theta}\left[U^{Q}(n, \theta)\right]}{\partial n}\right|_{n=n_{M}^{P}}=-\Delta \frac{3 a\left(4 n_{M}^{P}-1\right)\left[8\left(n_{M}^{P}\right)^{2}+1\right]-4 \Delta\left(n_{M}^{P}+1\right)\left(2 n_{M}^{P}+1\right)^{2}}{\left(4 n_{M}^{P}-1\right)^{3}\left(2 n_{M}^{P}+1\right)^{2}}<0 .
$$

Using (A14) and (A15), the free-entry effect in (25) is given by

$$
\begin{aligned}
\left(n_{M}^{P}-\right. & \left.n_{M}^{Q}\right)\left(\left.\frac{\partial \mathbb{E}_{\theta}[C S(n, \theta)]}{\partial n}\right|_{n=n_{M}^{P}}+\left.\frac{\partial n \mathbb{E}_{\theta}\left[U^{Q}(n, \theta)\right]}{\partial n}\right|_{n=n_{M}^{P}}\right) \\
& =\left(n_{M}^{P}-n_{M}^{Q}\right)\left\{\frac{4 a^{2} n_{M}^{P}}{\left(2 n_{M}^{P}+1\right)^{3}}-a \Delta \frac{8 n_{M}^{P}\left(4 n_{M}^{P}-1\right)+3}{\left[8\left(n_{M}^{P}\right)^{2}+2 n_{M}^{P}-1\right]^{2}}+\frac{4 \Delta^{2}\left(8 n_{M}^{P}+3\right)}{3\left(4 n_{M}^{P}-1\right)^{3}}\right\}>0,
\end{aligned}
$$

where the inequality follows from $n_{M}^{P}>n_{M}^{Q}$ (see Proposition 1) and the assumptions on the parameters of the model. Using (A8) and (A9), the vertical-restraints effect in (25) is given by

$$
n_{M}^{P} \mathbb{E}_{\theta}\left[U^{P}\left(n_{M}^{P}, \theta\right)-U^{Q}\left(n_{M}^{P}, \theta\right)\right]=-\frac{6 \Delta^{2} n_{M}^{P}}{\left(4 n_{M}^{P}-1\right)^{2}}<0 .
$$

Combining the free-entry effect and vertical restraints effect, we find that expression (25) for the difference in expected total welfare between the two legal regimes is negative.

Proof of Proposition 5. Substituting (A2), (A7) and (A4) into (26), we find after some manipulation that the difference

$$
\mathbb{E}_{\theta}\left[T W_{R}^{P}\left(n_{R}^{P}, \theta\right)\right]-\mathbb{E}_{\theta}\left[T W_{R}^{Q}\left(n_{R}^{Q}, \theta\right)\right]
$$


in expected total welfare between the two legal regimes is given by

$$
\begin{gathered}
a^{2} \frac{\left(n_{M}^{Q}-n_{M}^{P}\right)\left[2 n_{M}^{P}\left(2 n_{M}^{Q}-1\right)-2 n_{M}^{Q}-3\right]}{\left(2 n_{M}^{P}+1\right)^{2}\left(2 n_{M}^{Q}+1\right)^{2}}+ \\
-\frac{2 a \Delta\left(n_{M}^{P}-n_{M}^{Q}\right)\left[2 n_{M}^{P}\left(10 n_{M}^{Q}+1\right)+2 n_{M}^{Q}+3\right]}{\left(2 n_{M}^{P}+1\right)\left(4 n_{M}^{P}-1\right)\left(2 n_{M}^{Q}+1\right)\left(4 n_{M}^{Q}-1\right)}+ \\
+\Delta^{2} \frac{n_{M}^{P}\left(8 n_{M}^{P}+21\right)-4 n_{M}^{Q}\left[2 n_{M}^{P}\left(32 n_{M}^{P}+9\right)+3\right]+8\left(n_{M}^{Q}\right)^{2}\left(50 n_{M}^{P}-1\right)}{3\left(4 n_{M}^{P}-1\right)^{2}\left(4 n_{M}^{Q}-1\right)^{2}}
\end{gathered}
$$

As $n_{R}^{Q}>n_{R}^{P}$ (see Proposition 2), we find that this expression is positive for $n_{M}^{P} \geq 3$. Therefore, there exists a threshold $\widetilde{K}>0$ such that for $K<\widetilde{K}$ it holds

$$
\mathbb{E}_{\theta}\left[T W_{R}^{P}\left(n_{R}^{P}, \theta\right)\right]>\mathbb{E}_{\theta}\left[T W_{R}^{Q}\left(n_{R}^{Q}, \theta\right)\right]
$$

For $n_{M}^{P}=1$, the expression becomes negative. Then, there exists another threshold $\bar{K}$, with $\bar{K}>\widetilde{K}$, such that for $K>\bar{K}$ we have

$$
\mathbb{E}_{\theta}\left[T W_{R}^{P}\left(n_{R}^{P}, \theta\right)\right]<\mathbb{E}_{\theta}\left[T W_{R}^{Q}\left(n_{R}^{Q}, \theta\right)\right]
$$

We find from (A4) that

$$
\left.\frac{\partial n \mathbb{E}_{\theta}\left[\Pi^{Q}(n, \theta)\right]}{\partial n}\right|_{n=n_{R}^{P}}=-\frac{3 a^{2}\left(2 n_{R}^{P}-1\right)}{\left(2 n_{R}^{P}+1\right)^{3}}-\frac{4 \Delta^{2}\left(4 n_{R}^{P}+1\right)}{\left(4 n_{R}^{P}-1\right)^{3}}+6 a \Delta \frac{8\left(n_{R}^{P}\right)^{2}+1}{\left[8\left(n_{R}^{P}\right)^{2}+2 n_{R}^{P}-1\right]^{2}}<0,
$$

where the inequality follows from the assumptions on the parameters of the model. Using (A14) and (A16), the free-entry effect in (28) is

$$
\begin{aligned}
&\left(n_{R}^{P}-n_{R}^{Q}\right)\left(\left.\frac{\partial \mathbb{E}_{\theta}[C S(n, \theta)]}{\partial n}\right|_{n=n_{R}^{P}}+\left.\frac{\partial n \mathbb{E}_{\theta}\left[\Pi^{Q}(n, \theta)\right]}{\partial n}\right|_{n=n_{R}^{P}}\right) \\
& \quad=\left(n_{R}^{P}-n_{R}^{Q}\right)\left\{2 a \Delta \frac{4 n_{R}^{P}\left(5 n_{R}^{P}+1\right)+3}{\left[8\left(n_{R}^{P}\right)^{2}+2 n_{R}^{P}-1\right]^{2}}-a^{2} \frac{2 n_{R}^{P}-3}{\left(2 n_{R}^{P}+1\right)^{3}}-4 \Delta^{2} \frac{16 n_{R}^{P}+3}{3\left(4 n_{R}^{P}-1\right)^{3}}\right\} .
\end{aligned}
$$

The expression in braces is negative for $n_{R}^{P} \geq 4$. Therefore, there exists a threshold $\widehat{K}<\widetilde{K}$ such that for $K<\widehat{K}$ the free-entry effect is positive (recall from Proposition 2 that $n_{R}^{Q}>n_{R}^{P}$ ). Using (A2) and (A4), the vertical-restraints effect is

$$
n_{R}^{P} \mathbb{E}_{\theta}\left[\Pi^{P}\left(n_{R}^{P}, \theta\right)-\Pi^{Q}\left(n_{R}^{P}, \theta\right)\right]=\frac{3 \Delta^{2} n_{R}^{P}}{\left(4 n_{R}^{P}-1\right)^{2}}>0 .
$$

Combining the free-entry effect and vertical-restraints effect, we find that expression (28) for the difference in expected total welfare between the two legal regimes is positive for $K<\widetilde{K}$ and negative for $K>\bar{K}$. 
Proof of Proposition 6. Under laissez-faire, the social planner chooses the number $n$ of entrants in order to maximize the following expected total welfare

$$
\mathbb{E}_{\theta}\left[T W^{P}(n, \theta)\right] \triangleq \mathbb{E}_{\theta}[C S(n, \theta)]+n \mathbb{E}_{\theta}\left[\Pi^{P}(n, \theta)\right]+n \mathbb{E}_{\theta}\left[U^{P}(n, \theta)\right]-n K
$$

Using (A2), (A7) and (A8), the first-order condition for $n$ is given by

$$
a \Delta \frac{8 n(2 n+1)+3}{\left(8 n^{2}+2 n-1\right)^{2}}+\Delta^{2} \frac{9+20 n}{3(4 n-1)^{3}}-a^{2} \frac{2 n-3}{(2 n+1)^{3}}-K=0 .
$$

The socially optimal number $n_{T W}^{P}$ of entrants under laissez-faire satisfies condition (A17). Substituting the zero profit condition

$$
\mathbb{E}_{\theta}\left[\Pi^{P}\left(n_{M}^{P}, \theta\right)\right]-K=0
$$

into (A17) yields

$$
a \Delta \frac{4 n_{M}^{P}\left(16 n_{M}^{P}+5\right)-3}{\left[8\left(n_{M}^{P}\right)^{2}+2 n_{M}^{P}-1\right]^{2}}-2 \Delta^{2} \frac{32 n_{M}^{P}-15}{3\left(4 n_{M}^{P}-1\right)^{3}}-\frac{8 a n_{M}^{P}}{\left(2 n_{M}^{P}+1\right)^{3}}<0,
$$

where the inequality follows from the assumptions on the parameters of the model. The concavity of $\mathbb{E}_{\theta}\left[T W^{P}(n, \theta)\right]$ implies $n_{M}^{P}>n_{T W}^{P}$. Applying the implicit function theorem to (A17), we find from the concavity of $\mathbb{E}_{\theta}\left[T W^{P}(n, \theta)\right]$ that the sign of $\partial n_{T W}^{P} / \partial \Delta$ corresponds to the sign of the derivative of the left-hand side of the first-order condition (A17) with respect to $\Delta$, which is given by

$$
a \frac{8 n_{T W}^{P}\left(2 n_{T W}^{P}+1\right)+3}{\left[8\left(n_{T W}^{P}\right)^{2}+2 n_{T W}^{P}-1\right]^{2}}+2 \Delta \frac{20 n_{T W}^{P}+9}{3\left(4 n_{T W}^{P}-1\right)^{3}}>0,
$$

where the inequality follows from the assumptions on the parameters of the model. Moreover, applying the implicit function theorem to the zero profit condition

$$
\mathbb{E}_{\theta}\left[\Pi^{P}\left(n_{M}^{P}, \theta\right)\right]-K=0
$$

we find from

$$
\frac{\partial \mathbb{E}_{\theta}\left[\Pi^{P}(n, \theta)\right]}{\partial n}<0
$$

(see the proof of Proposition 1) that the sign of $\partial n_{M}^{P} / \partial \Delta$ corresponds to the sign of the derivative of (A2) with respect to $\Delta$, which is given by

$$
-2 \frac{12 a n_{M}^{P}-7 \Delta\left(2 n_{M}^{P}+1\right)-3 a}{32\left(n_{M}^{P}\right)^{3}-6 n_{M}^{P}+1}<0 .
$$

As $\partial n_{T W}^{P} / \partial \Delta>0$ and $\partial n_{M}^{P} / \partial \Delta<0$, we find that $n_{M}^{P}-n_{T W}^{P}$ decreases with $\Delta$.

Substituting the zero profit condition $\mathbb{E}_{\theta}\left[\Pi_{M-R}^{P}\left(n_{M-R}^{P}\right)\right]-K=0$ into (A17) yields

$$
-\frac{8 a^{2} n_{M-R}^{P}}{\left(2 n_{M-R}^{P}+1\right)^{3}}+\frac{56 \Delta^{2} n_{M-R}^{P}}{3\left(4 n_{M-R}^{P}-1\right)^{3}}+\frac{2 a \Delta n_{M-R}^{P}\left(20 n_{M-R}^{P}+7\right)}{\left[8\left(n_{M-R}^{P}\right)^{2}+2 n_{M-R}^{P}-1\right]^{2}}<0,
$$


where the inequality follows from the assumptions on the parameters of the model. The concavity of $\mathbb{E}_{\theta}\left[T W^{P}(n, \theta)\right]$ implies $n_{M-R}^{P}>n_{T W}^{P}$. Applying the implicit function theorem to the zero profit condition

$$
\mathbb{E}_{\theta}\left[\Pi_{M-R}^{P}\left(n_{M-R}^{P}, \theta\right)\right]-K=0
$$

we find from

$$
\frac{\partial \mathbb{E}_{\theta}\left[\Pi_{M-R}^{P}(n, \theta)\right]}{\partial n}<0
$$

(see the proof of Proposition 3) that the sign of $\partial n_{M-R}^{P} / \partial \Delta$ corresponds to the sign of the derivative of (A11) with respect to $\Delta$, which is given by

$$
-3 \frac{4 a n_{M-R}^{P}+2 \Delta\left(2 n_{M-R}^{P}+1\right)-a}{32\left(n_{M-R}^{P}\right)^{3}-6 n_{M-R}^{P}+1}<0 .
$$

As $\partial n_{T W}^{P} / \partial \Delta>0$ and $\partial n_{M-R}^{P} / \partial \Delta<0$, we find that $n_{M-R}^{P}-n_{T W}^{P}$ decreases with $\Delta$.

Under a ban on RPM, the social planner chooses the number $n$ of entrants in order to maximize the following expected total welfare

$$
\mathbb{E}_{\theta}\left[T W^{Q}(n, \theta)\right] \triangleq \mathbb{E}_{\theta}[C S(n, \theta)]+n \mathbb{E}_{\theta}\left[\Pi^{Q}(n, \theta)\right]+n \mathbb{E}_{\theta}\left[U^{Q}(n, \theta)\right]-n K
$$

Using (A7), (A4) and (A9), the first-order condition for $n$ is given by

$$
a \Delta \frac{8 n(2 n+1)+3}{\left(8 n^{2}+2 n-1\right)^{2}}-\frac{16 \Delta^{2} n}{3(4 n-1)^{3}}-a^{2} \frac{2 n-3}{(2 n+1)^{3}}-K=0 .
$$

The socially optimal number $n_{T W}^{Q}$ of entrants under a ban on RPM satisfies condition (A18). Substituting the zero profit condition

$$
\mathbb{E}_{\theta}\left[\Pi^{Q}\left(n_{M}^{Q}, \theta\right)\right]-K=0
$$

into (A18) yields

$$
a \Delta \frac{4 n_{M}^{Q}\left(16 n_{M}^{Q}+5\right)-3}{\left[8\left(n_{M}^{Q}\right)^{2}+2 n_{M}^{Q}-1\right]^{2}}-4 \Delta^{2} \frac{16 n_{M}^{Q}-3}{3\left(4 n_{M}^{Q}-1\right)^{3}}-\frac{8 a^{2} n_{M}^{Q}}{\left(2 n_{M}^{Q}+1\right)^{3}}<0,
$$

where the inequality follows from the assumptions on the parameters of the model. The concavity of $\mathbb{E}_{\theta}\left[T W^{Q}(n, \theta)\right]$ implies $n_{M}^{Q}>n_{T W}^{Q}$. Applying the implicit function theorem to (A18), we find from the concavity of $\mathbb{E}_{\theta}\left[T W^{Q}(n, \theta)\right]$ that the sign of $\partial n_{T W}^{Q} / \partial \Delta$ corresponds to the sign of the derivative of the left-hand side of the first-order condition (A18) with respect to $\Delta$, which is given by

$$
a \frac{8 n_{T W}^{Q}\left(2 n_{T W}^{Q}+1\right)+3}{\left[8\left(n_{T W}^{Q}\right)^{2}+2 n_{T W}^{Q}-1\right]^{2}}-\frac{32 \Delta n_{T W}^{Q}}{3\left(4 n_{T W}^{Q}-1\right)^{3}}>0
$$

where the inequality follows from the assumptions on the parameters of the model. Moreover, 
applying the implicit function theorem to the zero profit condition

$$
\mathbb{E}_{\theta}\left[\Pi^{Q}\left(n_{M}^{Q}, \theta\right)\right]-K=0
$$

we find from

$$
\frac{\partial \mathbb{E}_{\theta}\left[\Pi^{Q}(n, \theta)\right]}{\partial n}<0
$$

(see the proof of Proposition 1) that the sign of $\partial n_{M}^{Q} / \partial \Delta$ corresponds to the sign of the derivative of (A4) with respect to $\Delta$, which is given by

$$
-2 \frac{12 a n_{M}^{Q}-4 \Delta\left(2 n_{M}^{Q}+1\right)-3 a}{32\left(n_{M}^{Q}\right)^{3}-6 n_{M}^{Q}+1}<0 .
$$

As $\partial n_{T W}^{Q} / \partial \Delta>0$ and $\partial n_{M}^{Q} / \partial \Delta<0$, we find that $n_{M}^{Q}-n_{T W}^{Q}$ decreases with $\Delta$.

Substituting the zero profit condition

$$
\mathbb{E}_{\theta}\left[\Pi_{M-R}^{Q}\left(n_{M-R}^{Q}, \theta\right)\right]-K=0
$$

into (A18) yields

$$
-\frac{8 a^{2} n_{M-R}^{Q}}{\left(2 n_{M-R}^{Q}+1\right)^{3}}-\frac{16 \Delta^{2} n_{M-R}^{Q}}{3\left(4 n_{M-R}^{Q}-1\right)^{3}}+\frac{2 a \Delta n_{M-R}^{Q}\left(20 n_{M-R}^{Q}+7\right)}{\left[8\left(n_{M-R}^{Q}\right)^{2}+2 n_{M-R}^{Q}-1\right]^{2}}<0,
$$

where the inequality follows from the assumptions on the parameters of the model. The concavity of $\mathbb{E}_{\theta}\left[T W^{Q}(n, \theta)\right]$ implies $n_{M-R}^{Q}>n_{T W}^{Q}$. Applying the implicit function theorem to the zero profit condition

$$
\mathbb{E}_{\theta}\left[\Pi_{M-R}^{Q}\left(n_{M-R}^{Q}, \theta\right)\right]-K=0
$$

we find from

$$
\frac{\partial \mathbb{E}_{\theta}\left[\Pi_{M-R}^{Q}(n, \theta)\right]}{\partial n}<0
$$

(see the proof of Proposition 3) that the sign of $\partial n_{M-R}^{Q} / \partial \Delta$ corresponds to the sign of the derivative of (A12) with respect to $\Delta$, which is given by

$$
-\frac{3 a}{8\left(n_{M-R}^{Q}\right)^{2}+2 n_{M-R}^{Q}-1}<0 .
$$

As $\partial n_{T W}^{Q} / \partial \Delta>0$ and $\partial n_{M-R}^{Q} / \partial \Delta<0$, we find that $n_{M-R}^{Q}-n_{T W}^{Q}$ decreases with $\Delta$.

\section{References}

Asker, J. (2016). Diagnosing foreclosure due to exclusive dealing. Journal of Industrial Economics, 64(3), 375-410.

Blair, B. F., and Lewis, T. R. (1994). Optimal retail contracts with asymmetric information and moral hazard. Rand Journal of Economics, 25(2), 284-296. 
Blair, R. D., and Lafontaine, F. (2005). The economics of franchising. Cambridge University Press, Cambridge, UK.

Bonanno, G., and Vickers, J. (1988). Vertical separation. Journal of Industrial Economics, $36(3), 257-265$.

Bonnet, C., and Dubois, P. (2010). Inference on vertical contracts between manufacturers and retailers allowing for nonlinear pricing and resale price maintenance. Rand Journal of Economics, 41(1), 139-164.

Bonnet, C., Dubois, P., Villas Boas, S. B., and Klapper, D. (2013). Empirical evidence on the role of nonlinear wholesale pricing and vertical restraints on cost pass-through. Review of Economics and Statistics, 95(2), 500-515.

Bresnahan, T. F., and Reiss, P. C. (1990). Entry in monopoly markets. Review of Economic Studies, 57(4), 531-553.

Coughlan, A. T., and Wernerfelt, B. (1989). On credible delegation by oligopolists: A discussion of distribution channel management. Management Science, 35(2), 226-239.

Gal-Or, E. (1991a). Duopolistic vertical restraints. European Economic Review, 35(6), 12371253.

Gal-Or, E. (1991b). A common agency with incomplete information. Rand Journal of Economics, 22(2), 274-286.

Gal-Or, E. (1991c). Vertical restraints with incomplete information. Journal of Industrial Economics, 39(5), 503-516.

Gal-Or, E. (1992). Vertical integration in oligopoly. Journal of Law, Economics, ES Organization, $8(2), 377-393$.

Gal-Or, E. (1999). Vertical integration or separation of the sales function as implied by competitive forces. International Journal of Industrial Organization, 17(5), 641-662.

Gosh, A., and Morita, H. (2007). Free entry and social efficiency under vertical oligopoly. Rand Journal of Economics, 38(2), 541-554.

Hart, O., and Tirole, J. (1990). Vertical integration and market foreclosure. Brookings Papers on Economic Activity. Microeconomics, 1990, 205-286.

Jia, P. (2008). What happens when Wal-Mart comes to town: An empirical analysis of the discount retailing industry. Econometrica, 76(6), 1263-1316.

Jullien, B., and Rey, P. (2007). Resale price maintenance and collusion. Rand Journal of Economics, 38(4), 983-1001.

Kastl, J., Martimort, D., and Piccolo, S. (2011). "When should manufacturers want fair trade?": New insights from asymmetric information when supply chains compete. Journal of Economics \& Management Strategy, 20(3), 649-677. 
Katz, M. L. (1991). Game-playing agents: Unobservable contracts as precommitments. Rand Journal of Economics, 22(3), 307-328.

Lafontaine, F., and Shaw, K. L. (1999). The dynamics of franchise contracting: Evidence from panel data. Journal of Political Economy, 107(5), 1041-1080.

Lafontaine, F., and Slade, M. E. (1997). Retail contracting: Theory and practice. Journal of Industrial Economics, 45(1), 1-25.

Mankiw, N. G., and Whinston, M. D. (1986). Free entry and social inefficiency. Rand Journal of Economics, 17(1), pp. 48-58.

Martimort, D. (1996). Exclusive dealing, common agency, and multiprincipals incentive theory. Rand Journal of Economics, 27(1), 1-31.

Martimort, D., and Piccolo, S. (2007). Resale price maintenance under asymmetric information. International Journal of Industrial Organization, 25(2), 315-339.

Martimort, D., and Piccolo, S. (2010). The strategic value of quantity forcing contracts. American Economic Journal: Microeconomics, 2(1), 204-229.

Mathewson, G. F., and Winter, R. A. (1984). An economic theory of vertical restraints. Rand Journal of Economics, 15(1), 27-38.

McAfee, R. P., and Schwartz, M. (1994). Opportunism in multilateral vertical contracting: Nondiscrimination, exclusivity, and uniformity. American Economic Review, 84(1), 210-230.

Motta, M. (2004). Competition policy: Theory and practice. Cambridge University Press, Cambridge, UK.

Myerson, R. B. (1982). Optimal coordination mechanisms in generalized principal-agent problems. Journal of Mathematical Economics, 10(1), 67-81.

Pagnozzi, M., Piccolo, S., and Bassi, M. (2016). Entry and product variety with competing supply chains. Journal of Industrial Economics, 64(3), 520-556.

Raith, M. (2003). Competition, risk, and managerial incentives. American Economic Review, 93(4), 1425-1436.

Reisinger, M., and Schnitzer, M. (2012). Successive oligopolies with differentiated firms and endogenous entry. Journal of Industrial Economics, 60(4), 537-577.

Rey, P., and Stiglitz, J. (1995). The role of exclusive territories in producers' competition. Rand Journal of Economics, 26(3), 431-451.

Rey, P., and Tirole, J. (1986). The logic of vertical restraints. American Economic Review, 76(5), 921-939.

Spengler, J. J. (1950). Vertical integration and antitrust policy. Journal of Political Economy, $58(4), 347-352$. 
Suzuki, J. (2013). Land use regulation as a barrier to entry: Evidence from the Texas lodging industry. International Economic Review, 54(2), 495-523.

Telser, L. G. (1960). Why should manufacturers want fair trade?. Journal of Law and Economics, $3,86-105$.

Tyagi, R. K. (1999). On the effects of downstream entry. Management Science, 45(1), 59-73.

Vickers, J. (1985). Delegation and the theory of the firm. Economic Journal, 95, 138-147.

Vives, X. (1999). Oligopoly pricing: Old ideas and new tools. MIT Press, Cambridge, MA. 